\title{
Compliance and application tests of usability guidelines about giving information quickly and comprehensibly
}

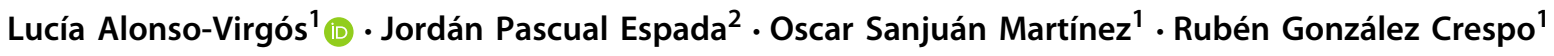

Received: 2 April 2020 / Accepted: 4 September 2020 / Published online: 7 October 2020

(c) The Author(s) 2020

\begin{abstract}
The objective of this publication is to analyze compliance with the web usability guidelines on Giving information quickly and comprehensibly. The behavior of 20 IT engineers without experience in web usability is analyzed to collect data on the application and compliance of each of the studied guidelines. The objectives are: (1) make a list of recommendations on the presentation of information and possible actions in a quickly understandable way. And highlight the most forgotten guidelines or the worst followed by web developers to think about the importance of offering specific training in this field. (2) Know the most important guidelines according to the participants themselves. To obtain the results, user tests are performed that evaluate the most ignored and applied guidelines. And its correct compliance is studied, since the participants do not have experience in web usability. Besides, interviews are conducted to find out which are the guidelines that they consider most important. It is expected to know if there are guidelines that apply intuitively and why. It is also intended to know if this innate application is helpful or compliance is wrong and needs specific training.
\end{abstract}

Keywords Information · Quickly · Comprehensibly · Guidelines · Recommendations · Web usability

\section{Introduction}

Usability web is the field that aims to facilitate a person to use a website. Many "ideas" have been published to improve the usability of websites [1]. These "ideas" are classified into heuristics, guidelines, usability recommendations, etc., [2]. Heuristics, guidelines, and guidance are different concepts.

The best-known heuristics were published in ten Usability Heuristics for User Interface Design by Jakob Nielsen's (1995) [3]. These recommendations are design principles that allow the user to interact easily. Heuristics are useful, but

Lucía Alonso-Virgós

lucia.alonso.virgos@unir.net

Jordán Pascual Espada

jordansoy@gmail.com

Oscar Sanjuán Martínez

oscar.sanjuan@unir.net

Rubén González Crespo

ruben.gonzalez@unir.net

1 Universidad Internacional de La Rioja, Av. de La Paz, 137, 26006 Logroño, La Rioja, Spain

2 Universidad de Oviedo, Calle Valdés Salas, 11, 33007 Oviedo, Asturias, Spain experts have shown that due to their theoretical approach, they are not the best answer to specific design problems [4].

The guidelines are a bit different, but their purpose is the same as heuristics [5, 6]. About the guidelines, they are not always the best option, because they are still too theoretical. Its foundations are not presented in a theoretical framework broad enough to determine generalities [6].

Usability recommendations are most useful for setting standards [7]. But although there is a multitude of research papers that include lists of recommendations [7], to date, they have not been classified or ordered in a standardized manner. Creating an organized order would be very useful for web developers.

In this work, first, the recommendations are drawn from different sources. 103 usability recommendations accepted for websites have been compiled. Within this selection, recommendations for specific domains have been avoided [8]. This selection of usability recommendations is divided into five groups [8].

The objective of the division is to offer an order that classifies recommendations to avoid repetitions and to help them be standardized. The proposed groups are: 


\section{Recommendations to reduce "noise"}

1. Follow conventions.

2. Give information quickly and comprehensibly.

3. Efficient and understandable controls for users to enter information.

4. Give answers descriptive and understandable to the actions of the users.

After publishing this orderly grouping of recommendations [8] and evaluating the recommendations of the group (1) recommendations to reduce "noise" in "Compliance analysis and usability application and recommendations of web developers" [8], the recommendations of the group (4) efficient and understandable controls for users to enter information in "Analysis of compliance and application of usability guidelines on efficient and understandable controls" [9], group recommendations (2) follow the conventions, this document has the purpose of grouping, and analyzing group recommendations (3) give information quickly and comprehensively. Of those 103 recommendations, there are 24 useful recommendations on (3) give information quickly and comprehensively, all of which have been extracted from [10-20]. User tests and interviews with web developers are conducted without training in web usability to evaluate each of the recommendations.

This research aims to select and classify the most relevant and generic guidelines. After doing this, it is intended to know if web developers trained to create websites need concrete preparation in web usability, or if they apply the recommendations intuitively without the need for training.

Objective 1 aims to know the level of application and compliance of each of the Group's guidelines (3) by web developers without training in web usability. Objective 2 aims to know the degree of importance that web developers give each recommendation after understanding its purpose; that is, after receiving concrete training.

This article is organized as follows: "Background" is given in Sect. 2. Section 3 offers an analysis of usability assessments, heuristic definitions, guidelines and recommendations, and web development. We show how recommendations were extracted and grouped and how each one is evaluated. In Sect. 4 "Recommendations", we present the recommendations of the group (3). In Sect. 5 "Results of the experiment" we offer the results for each of the recommendations. In Sect. 6 "Evaluation", the results are evaluated. In Sect. 7 "Discussion", the best and worst recommendations valued by volunteers are highlighted. The conclusions are drawn in Sect. 8. In Sect. 9, we propose some lines of future research.

\section{Background}

\section{Usability evaluation}

Usability is the degree of ease, effectiveness, and efficiency in which a website is managed [10]. The user experience [10] aims to analyze this use thanks to the collaboration of a specific user. Therefore, usability is an essential part of user experience.

In this paper, we analyze the usability evaluation methods to evaluate usability through expert reviews. Although only evaluation methods are used, all types of existing evaluations are cited in this section. The evaluation methods are divided into three types:

(i) Usability inspections These inspections are abstract ideas supported by studies or observation and are based on expert analysis. The most common are heuristic evaluations, cognitive routes, and patterns and/or checklists $[6,11,12]$. These tests evaluate concrete actions [13] or specific problems during navigation $[14,15]$.

(ii) User-centered methods In these tests, there is user participation, so they are considered more practical than the previous ones. They are tests, interviews, and/or physiological measurements [16-18]. The use of a website is analyzed observing the possible problems to try to solve them. The interviews intend to know the opinions of the users. The user is asked a series of questions about their behavior, attitude, thoughts, and feelings before an aspect of the website. Monitoring consists of evaluating the physiological responses of users; for example, using a tracker to measure eye movement and know which areas of the interface most are visited.

Three techniques measure the efficiency in the interaction of the user with the computer, the memory capacity that a user presents after browsing a website that he had not visited for a while, and the efficiency performing tasks on a website. These assess satisfaction by analyzing the facial expressions of users [19].

(iii) Also, there is a third method of website evaluation: an automatic evaluation! In this work, it is not considered, because usability experts recommend that it be the people who make evaluations. This is because the evaluation aims to discover the ease of use of a website. The ease of use comes from the intuition of the user as a person when there is no experience or training. That is why, it is considered more useful for evaluations to be carried out by a person than by an automatism [20].

An advantage of automatisms is that they are completely objective in their evaluation, while one person can extract different results from another person [32-35].

In this investigation, the proposals are evaluated through interviews aimed at web developers with no usability experience who also think like users. Evaluations are also evaluated through expert inspections. 


\section{Heuristics, guidelines, and recommendations}

The heuristic method aims to discover the best form of human-computer interaction. In this field, Nielsen [21, 22] and other proposals useful only for specific domains [23-26] stand out. These proposals seek to alert existing problems to avoid errors [27]. They are not useful for assessing general web design problems [4].

For example, "The website must differentiate links in plain text" or "A single column paragraph increases the reading speed in multi-column paragraphs" [6,28]. These are the necessary guidelines for specific websites.

Also, there is no standard to follow $[6,29,30]$.

This work aims to select the most important and generic guidelines. Some of the resources to analyze these guidelines were obtained from [6,11, 27, 28, 30-33]. 103 generic recommendations are extracted and analyzed $[8,28,33]$ to choose only those useful for any domain.

\section{Web developers}

A web developer is technically capable of developing a web interface, but does not always show that he is trained in human-computer interactions. Therefore, their developments sometimes do not meet the needs of users [34] or do not meet the specific needs of a domain $[35,36]$. This "ignorance" makes the application of web usability guidelines unhelpful [37]. This research aims to discover if there is intuition during the application of usability guidelines and if such an application is correct. It is intended to demonstrate that there are guidelines that are intuitively applied and others that are not used, and the reason for each situation.

\section{Research design}

This work intends two purposes: (1) order and classify all existing recommendations on web usability. Today, there is no standardized list of useful recommendations applicable to all websites. (2) This publication focuses on the group. (3) Give information quickly and comprehensively, of that classification, and intends to evaluate the 24 existing guidelines on "information".

It also seeks to evaluate each of the group's recommendations (3) with the help of 20 web engineering graduate students. The purpose is to know if these guidelines are applied innate and are correctly fulfilled without the need for training. We also want to know the importance that these development give each recommendation once they understand their purpose.

\section{Classification of recommendations}

The 103 recommendations were extracted from different sources $[6,11,42-46]$ and divided into five groups by Jordán Espada. He analyzed the 103 recommendations and their objectives and looked for similarities. He found five viable similarities, differentiated by their purpose.

1. Recommendations to reduce "noise".

2. Follow conventions.

3. Give information quickly and comprehensibly.

4. Efficient and understandable controls for users to enter information.

5. Give answers descriptive and understandable to the actions of the users.

This grouping proposal has been designed and serves as didactic material in the Master in Web Engineering of the University of Oviedo.

Figure 1 shows the grouping of recommendations in detail [38]. The 103 recommendations extracted are divided into five groups of 16, 8, 24, 17, and 4 recommendations.

As indicated in the figure, repeated or specific recommendations are eliminated.

\section{Evaluation of the recommendations}

The behavior of 20 Spanish computer engineers is studied to meet the objectives of this investment. It is intended to discover if when a web developer without usability experience applies a usability recommendation, it is because there is intuition. If they are not applied intuitively, it follows that training is needed.

Of the 20 students, 5 are women and 15 are men with an average age of 23 years. All are students of the Master in Computer Engineering today. They have a degree in Web Engineering, so everyone has the capacity and technical capacity to develop a website. However, none studied or have work experience in web usability. Usability web is a syllabus that will be taught in the Master after the experiment in this article.

None knows web usability, but everyone has a high level of knowledge in web development, so our team intends to know if a web developer of these characteristics can innate application of any of the usability recommendations, since usability is the ease of use and these developers are also users. It also seeks to know if the recommendations applied are met correctly. And, finally, it is intended to know the importance that the web developers themselves give to each recommendation, once they have been trained in usability.

Each student is assigned a theme (banking, restaurants, etc.) with which they must design a website for the experiment. 


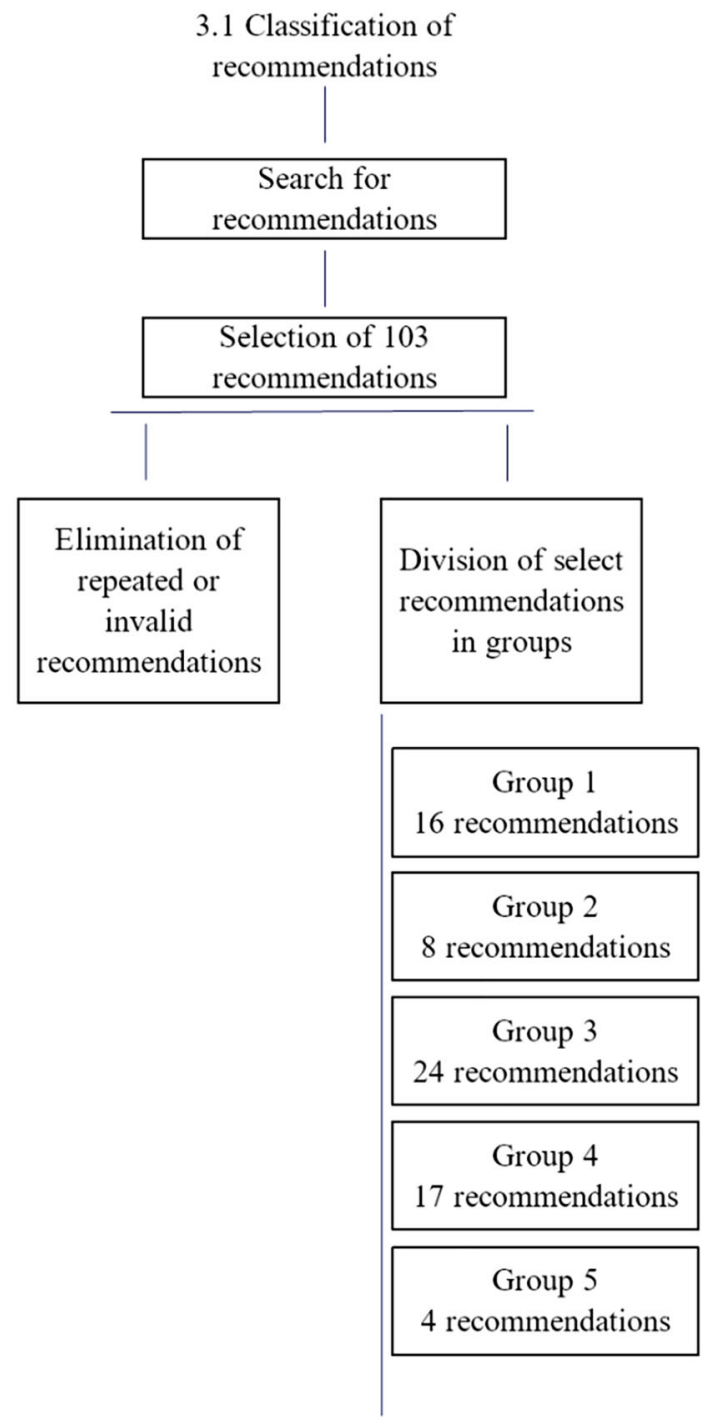

Fig. 1 Classification of recommendations

You get 20 different websites created by developers without usability training. Web engineers are trained in usability so they can evaluate their web designs. For this research, they receive training on the 24 recommendations collected and grouped in the Group (3).

The objective is to know the importance that a web developer recently trained in usability attributes to each of the recommendations. And, on the other hand, to know if any of them apply the usability recommendations naturally. And, if so, if you comply correctly, see Fig. 2.

To know the importance that each web developer gives to each recommendation, surveys are carried out, see Fig. 2, left side. The hierarchy of importance is measured with a score of 0-10 (Objective 1). As stated above, this survey is carried out after training in web usability, so that participants know the function of each recommendation, whether or not they
3.2 Evaluation of group 2

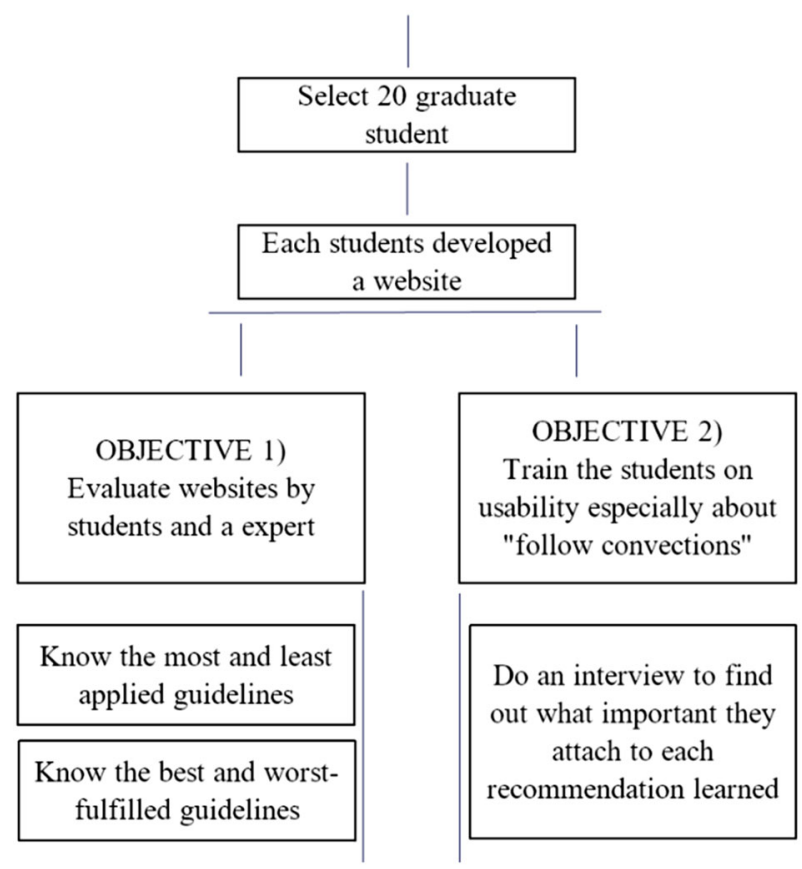

Fig. 2 Evaluation of group 2. Objective 1 and Objective 2

have applied it in their web developments. The results of the critical measurement are shown in Sect. 5 (Fig. 13).

Each website is tested below. The tests are performed by the participants themselves, assisted by a usability expert supervisor.

The evaluations are qualified. An applied recommendation is scored with 1 , and an unapplied recommendation is scored with 0 . The application measures the intention to use the recommendations. These results can provide useful information on whether recommendations are innately used by inexperienced developers.

The degree of compliance is also scored with values from 0 to 5.0 means that the recommendation is not met correctly. 5 means that the recommendation is met successfully. A recommendation may have value 1 in the application and 0 in compliance. This means that the recommendation is applied innate, because it is considered useful, but incorrectly (Objective 2). The tests performed can be found in Sect. 5 of this article.

\section{Recommendations extracted and grouped}

This section presents each of the recommendations on information. It is considered that, within this group, there are 24 essential recommendations, which are the following: Group 3-give information quickly and comprehensibly. 


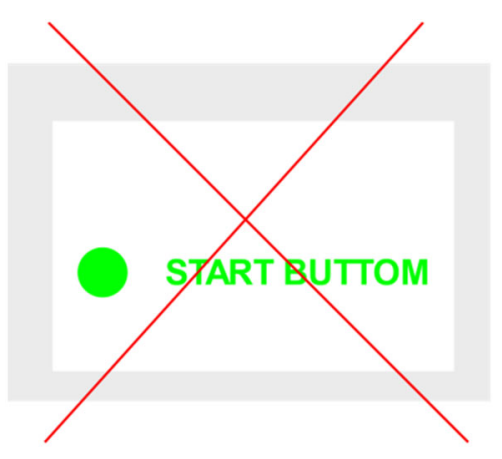

START BUTTOM

Fig. 3 Identifiable clickable areas. No-compliance and compliance

\section{Recommendation A: identifiable clickable areas of enough size}

This guideline seeks that the user does not need to think too much when he is going to click a button. This requires that the button be evident, as seen in Fig. 3 .

The user must quickly recognize where he can press. It is recommended to visually highlight the button or that the button changes upon receiving the focus.

It is also important that the button is sized enough to be comfortably pressed. It would be necessary to review inputs, buttons, links with very short texts, and very small images.

The time required to move the cursor to an object depends on the distance. The greater the distance, the greater the time required [39].

Figure 3 shows two screens with the same button. The button on the top screen is not obvious. It has no delimitation, volume, or color that stands out. However, the button on the bottom screen is delimited. In this case, the button is evident and prevents the user from thinking.

Figure 4 shows two forms. The upper form presents the fields that are too small. It also has a small submit button. And there is too much space between the fields and the button. The lower form has an appropriate size in the fields and on the button. Space is better distributed and helps the user.

\section{Recommendation B: use color to increase recognition speed}

With this guideline, it is possible to communicate through text and color. The information issued must be key. And it is
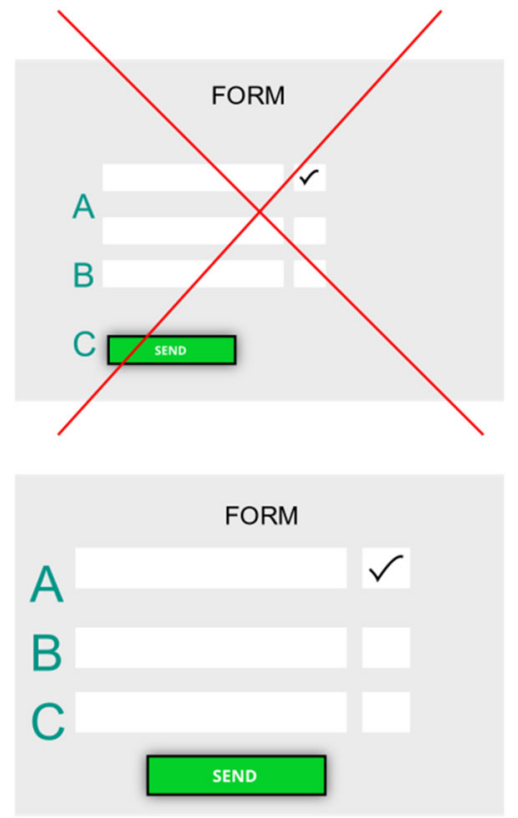

Fig. 4 Identifiable clickable areas of enough size. No-compliance and compliance

preferable not to abuse the number of colors with meaning. Limiting the number of colors is more effective [40].

Figure 5 shows two listings. In the listing above, there are several poorly identifiable elements. In the list below, each element is highlighted with a color. This color depends on its state. For example, a sent message is colored green. A message with a shipping error is colored red.

\section{Recommendation C: use of images to increase recognition speed}

This guideline reinforces any concept through icons. To gain effectiveness, the icons must be easy to remember and identify [40].

It is recommended to use this guideline in menus. For example, with home icons, notifications, messages, etc.; to differentiate categories; for example, the category of sale of motor vehicles and category of a real estate sale; for actions; for example, a new message, copy, paste, etc. The images not only identify the action but also highlight it.

This guideline is also recommended in items of options lists. In this case, less prominent images are preferred. For example, in a list of countries, it is advisable to include the flag.

Other uses of this guideline are in states, properties, lists, and profiles. For example, if there is an icon of an airplane in a state in a profile, it can mean that the owner of the profile is on vacation. The image gives a meaning (include tooltip) and can avoid long texts. 


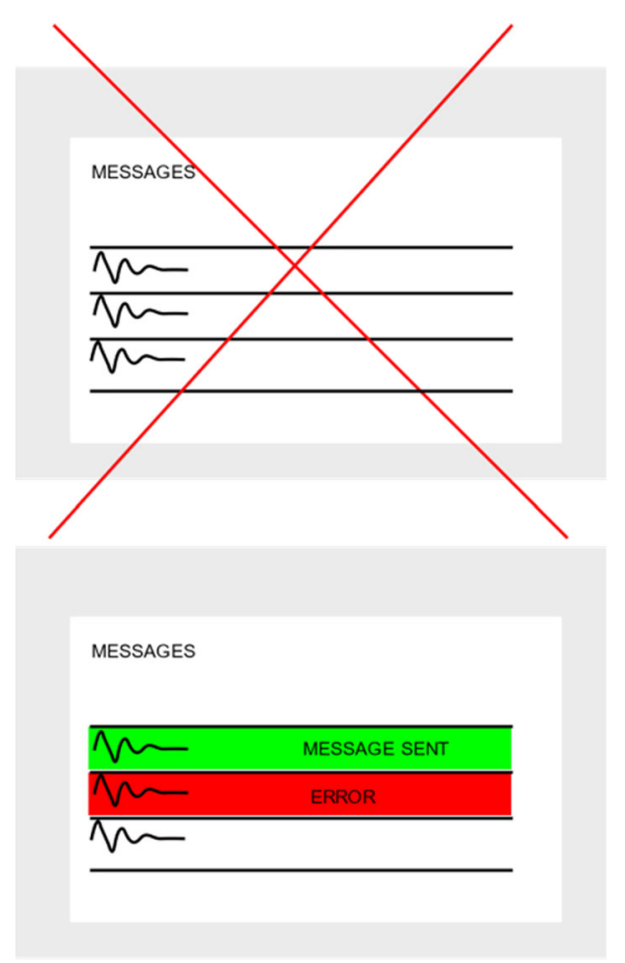

Fig. 5 Avoid "false clickable elements". No-compliance and compliance

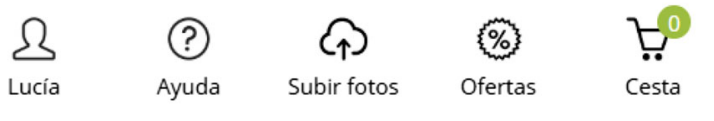

Fig. 6 Menu with icons that help to identify each section [41]

In data with percentages, it is also useful or in steps of a process that involves several steps.

Figure 6 shows a menu with icons that help to identify each section.

\section{Recommendation D: highlighting dynamic changes on the website}

This guideline aims to highlight new information with dynamic elements. For example, through transitions or other effects [42].

A web page is shown in Fig. 7. In it, the cursor is on the "magic" button. Clicking the web page offers an animation that ends in a small design change that helps the user in understanding.

\section{Recommendation E: limit the extension of tasks}

This guideline recommends using one main task per page. This task should be highlighted within the rest of the possible tasks. If the task is long, it should be divided into sub-tasks
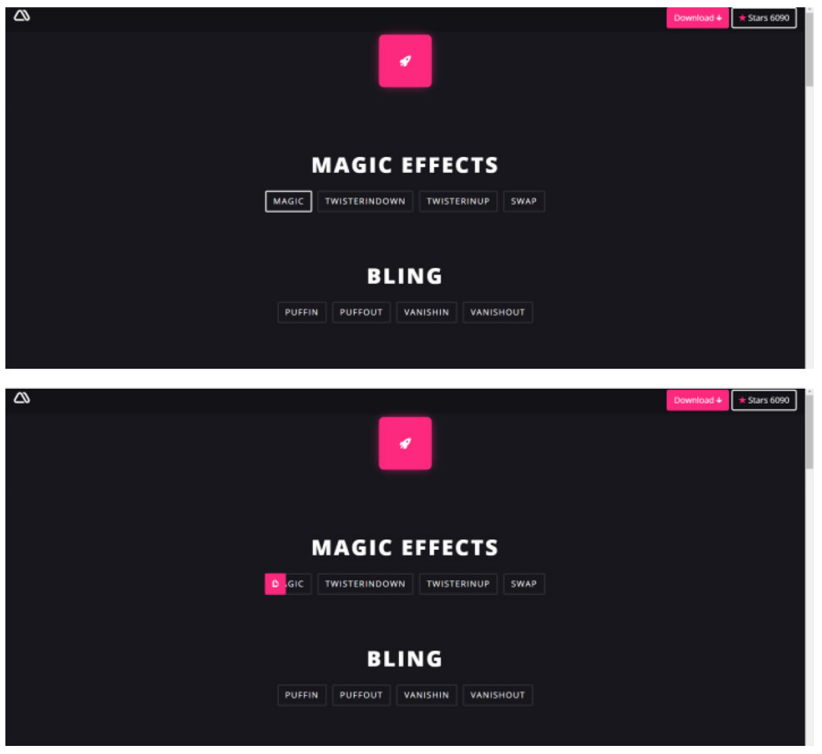

Fig. 7 Highlighting dynamic changes on the website, before and after the click [43]

\section{facebook}

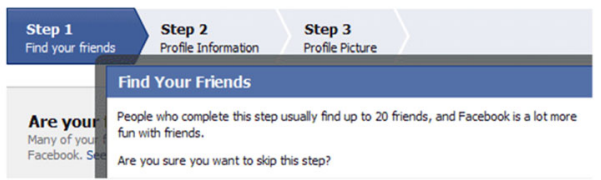

Fig. 8 Steps that a user must take on Facebook to find friends. Step 1. Find your friend [45]

[44]. To perform this division of tasks well, you can do with users. They should be short. For example, sub-task (1) shipping address, sub-task (2) payment, etc.

Figure 8 shows the steps that a user must take on Facebook to find friends.

\section{Recommendation F: task progress report}

This guideline completes the previous one. Not only must indicate the number of steps that the user must take, but also highlight what is at each moment [44].

"Progress indicator" would be the percentage made. The step in which the user is. The missing steps to finish a task. Figure 8 shows step 1, where the user is.

\section{Recommendation G: repetition of main actions}

This guideline is intended to help the user navigate faster. When the user does not find an action, it takes more time to complete a task. That is why, it is recommended to repeat the main actions. The same main action is performed from sev- 


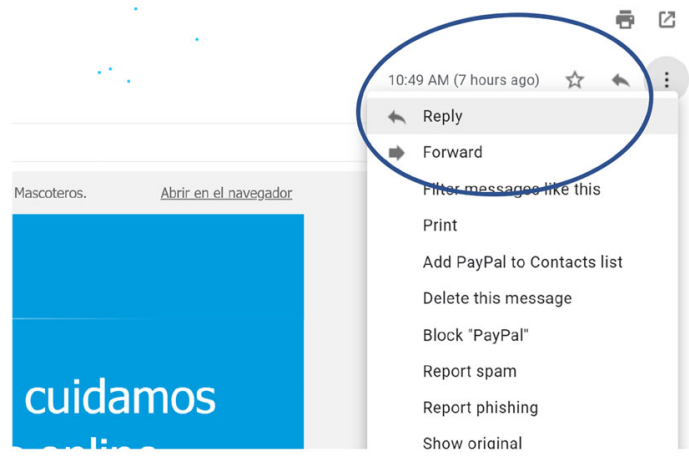

Fig. 9 Options to respond to the mail [47]

eral different parts from page (1-3). The action must always be positioned in logical sites [46].

In Fig. 9, there are two options for the user to respond to the mail.

\section{Recommendation H: grouped textual listings}

This guideline recommends grouping the listings. Listings are analyzed more quickly if they are grouped. Especially the listings with a lot of text. For example, when this text implies actions or information, it is easier to understand if it is grouped [48].

There are always several ways to group. You have to use the most logical. For example, conceptually, alphabetically, by year, country, price, valuation, etc.

In Fig. 10, there is a list with a lot of content. In the image above that textual content does not appear ordered or grouped and makes it difficult to read. In the image below, it is grouped with outstanding titles. This facilitates quick reading.

\section{Recommendation I: list of elements. Show key information}

With this guideline, the previous one is completed. It is recommended to show the most relevant information or use common. It is also preferable to avoid entering the view in detail (preliminary decision) [49].

Several items available for purchase are presented in Fig. 11. Any of them who do not receive the focus presents the key information. For example, the name of the article, measures, availability, brand, and price. When the item receives the focus it also includes the option to add it to the shopping cart and the type of shipping available.

\section{Recommendation J: list of elements. Limit key information}

It is appropriate to display $1-5$ properties on the screen. If they show more, they could make understanding difficult.

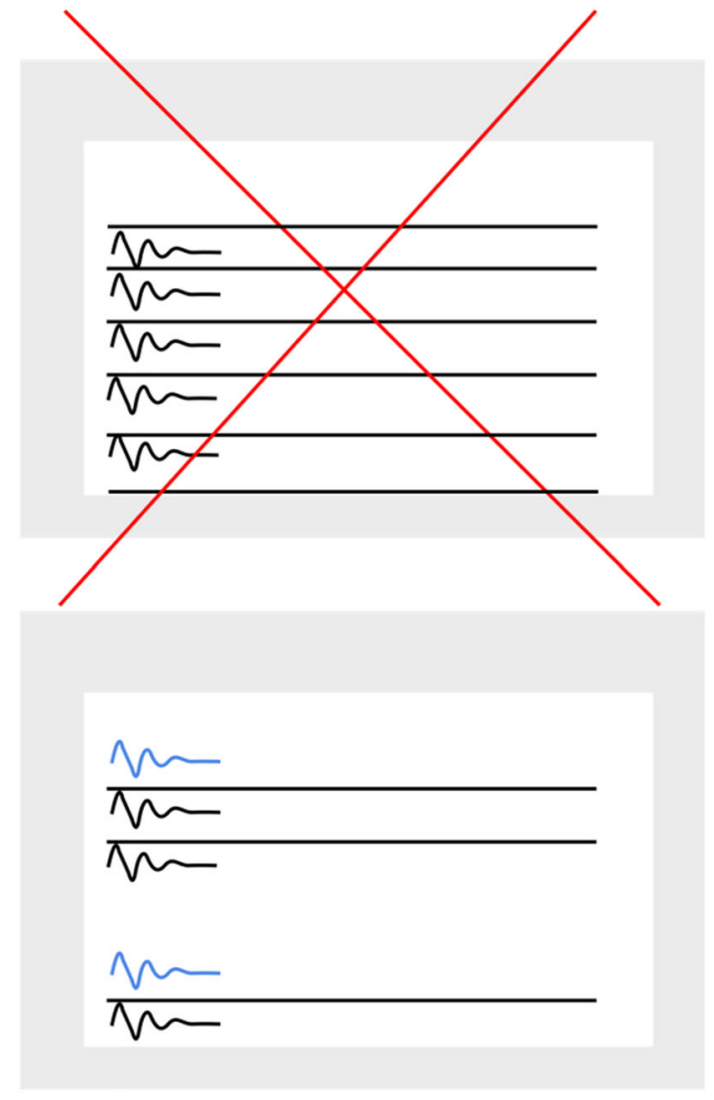

Fig. 10 Grouped textual listings. No-compliance and compliance

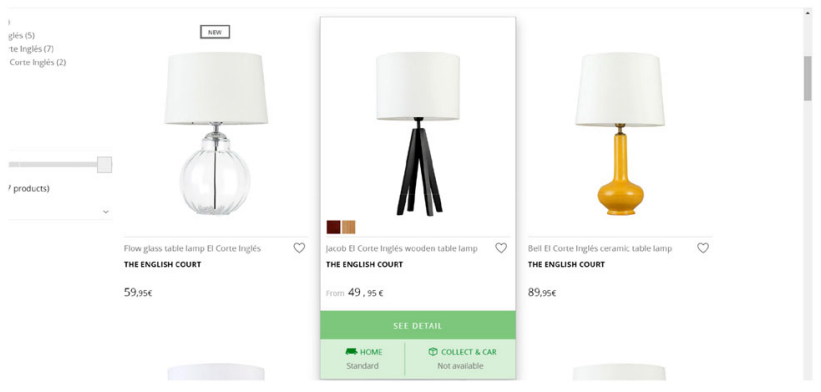

Fig. 11 List of elements. Show key information [50]

They can be displayed more in detail view or by placing the focus on the element [49].

Figure 12 shows a screen with several articles. The above figure presents the articles, so that the web page complies with the previous guideline, but does not show the specific characteristics of each article. In the image below, its status is highlighted. For example, paid items or items for sale.

A highlighted article of a set of articles is shown in Fig. 12. The featured article offers additional information. 


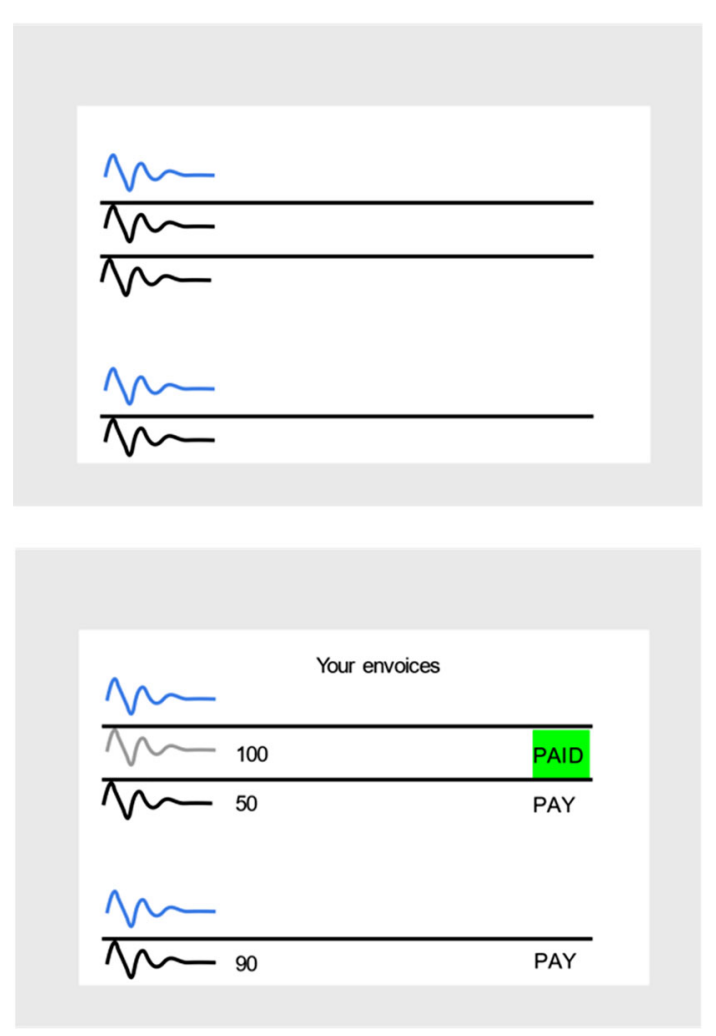

Fig. 12 List of elements. Show key information. No-compliance and compliance

\section{Recommendation K: list of elements. Avoid zigzag}

This guideline helps the user not to get tired. It can be applied if the properties of the elements are compared with the same number of properties. Its properties must be grouped visually. For example, in the same line, with the same color, or with the same source [49].

Figure 13 shows a t-shirt shopping web page. In the image above, the shirts are ordered in vertical order. This forces the user to make a zigzag eye movement to compare the properties of each element. In the image below, the shirts are ordered horizontally. In this way, the tracking is more comfortable for the user, because he can compare the same properties in the same focal area.

\section{Recommendation L: element listings. Sorting, filtering, and search mechanisms}

This guideline is intended to help the management of elements. The user loses more time when there are many messy items. For this reason, it is recommended to order them. For this, a useful sorting, filtering, or search mechanism must be included [49].

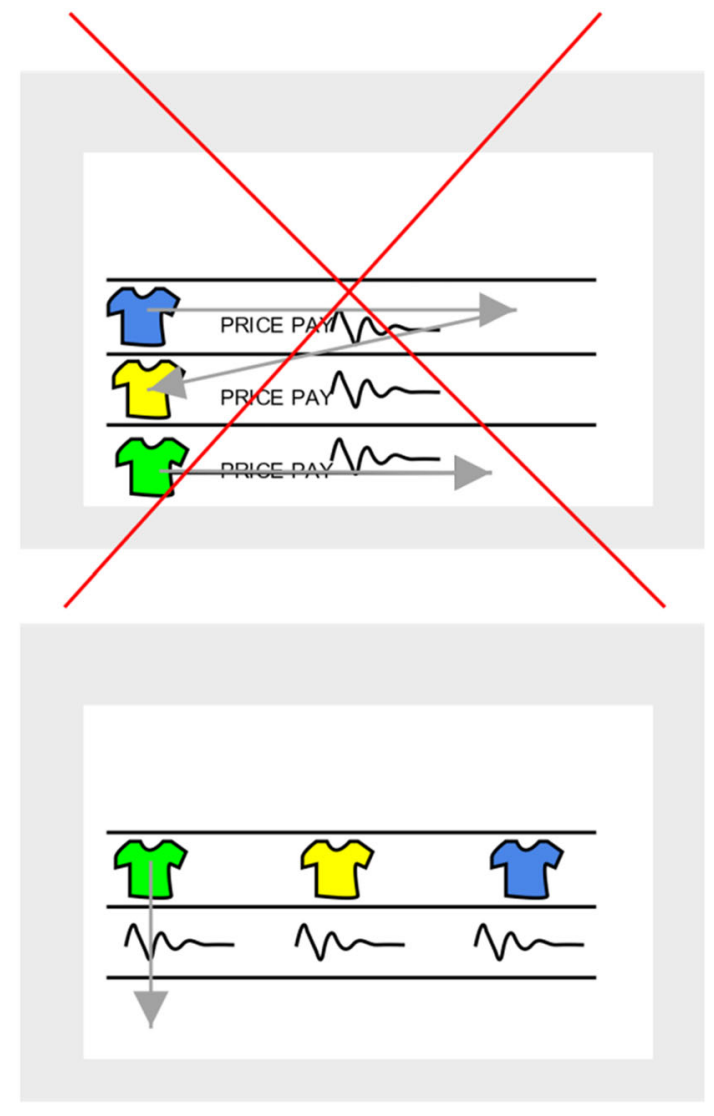

Fig. 13 Proper use of common icons. No-compliance and compliance

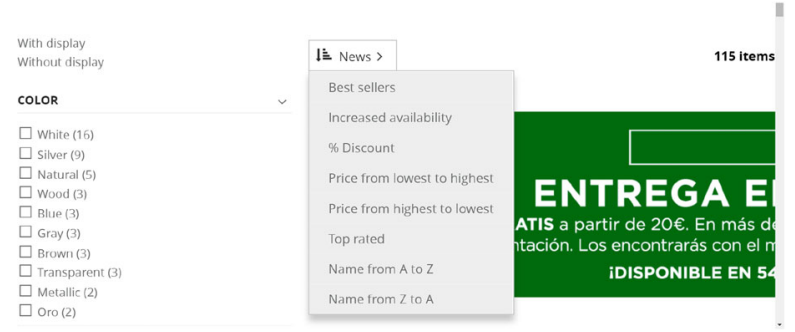

Fig. 14 Element listings. Sorting, filtering, and search mechanisms [50]

Figure 14 shows a sort of drop-down filtering. This makes it more comfortable to find an item. For example, order by the lowest price.

\section{Recommendation M: list of elements. Highlight item with focus}

This guideline aims to help with the selection of elements within a list. It is recommended to properly highlight the selected item with a focus. By getting the focus you could also show more information or actions [49].

Figure 15 shows an article selected from a list of articles. 


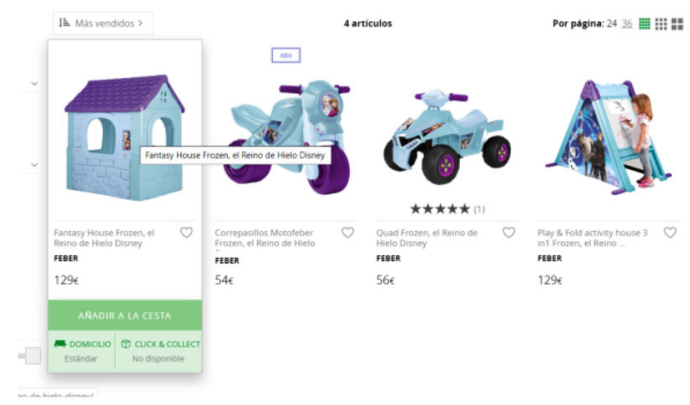

Fig. 15 List of elements. Highlight item with a focus [50]

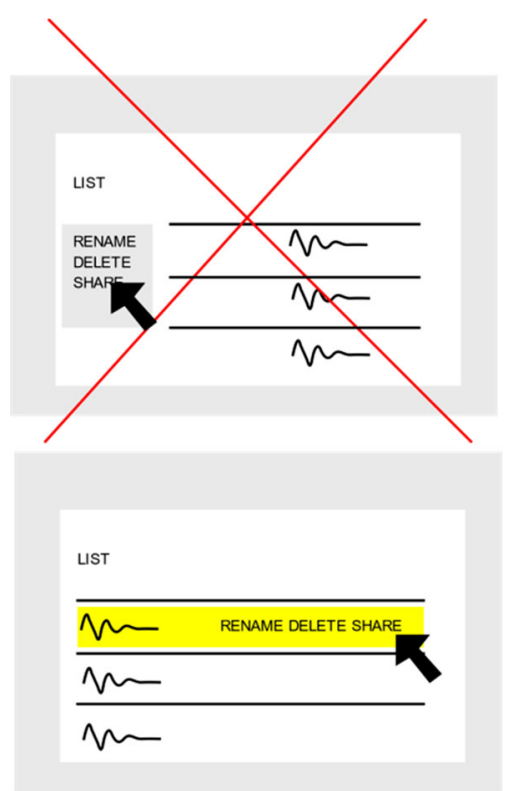

Fig. 16 List of elements. Avoid manipulation through menus. Nocompliance and compliance

\section{Recommendation N: list of elements. Avoid manipulation through menus}

Direct manipulation is usually faster if it is within the information itself than in an external menu. Direct manipulation can be combined with element selection plus action applications [49].

Figure 16 shows two web pages. In the upper one, there is an external menu with important information for each of the three elements offered on the website. It means that each of the elements can be renamed, deleted, or shared. This can be confusing for the user, because he must make an element selection and an active application in different places. On the lower web page, however, only the three elements are shown. When one of them receives the focus, it stands out. Also, it presents the three available actions, renames, deletes, and shares. In this way, the user clicks on the element which he wants and only in this one the actions are shown, so that the

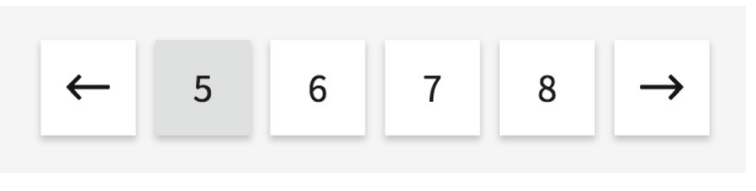

Fig. 17 List of elements. Avoid scroll [47]

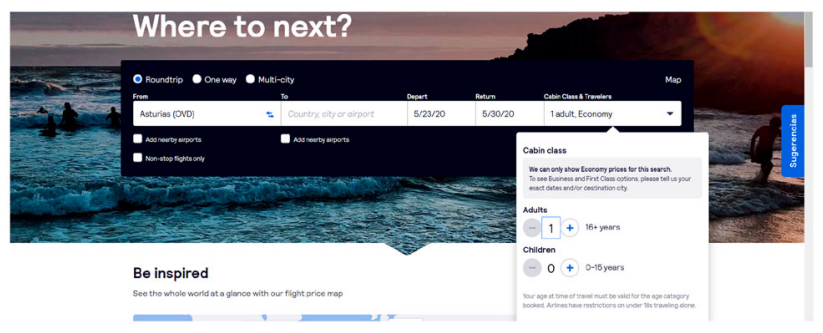

Fig. 18 List of items-show the number of items listed [51]

direct manipulation combines element selection and action application.

\section{Recommendation 0: list of elements. Avoid scroll}

This guideline recommends not presenting listings with too many elements on the same web page. To avoid doing this, it is recommended to use some paging mechanism. For example, explore the paging systems of several important sites. Another way to comply with this guideline is to show which is the current web page and the next ones closest to the current web page, that is, previous and next. Or those at the extremes, that is, first and last [49].

Figure 17 shows a paging system that highlights the web page where the user is located, 8. It also includes the next two web pages closest to the current one using the "previous" and "next" buttons. In this example, four more numbered pages are presented, so that the user can move faster in his search.

\section{Recommendation P: list of items. Show the number of items listed}

This guideline aims to offer the user extra information to their search when it comes to a list. In a search in which the result is a list of elements, the user needs to know how many elements have been found. Knowing this, you can estimate the time; you will spend to review them all and decide if you prefer to do an alternative search [49].

When the result of a search is a listing, it is recommended to offer a search filter [44].

Figure 18 shows a web page that offers a travel search service. There are five results after entering the destination in the search field. To help the user, the website helps to filter those results with drop-down lists that differentiate the shipping company, the port of embarkation, the departure month, and the duration of the trip. 


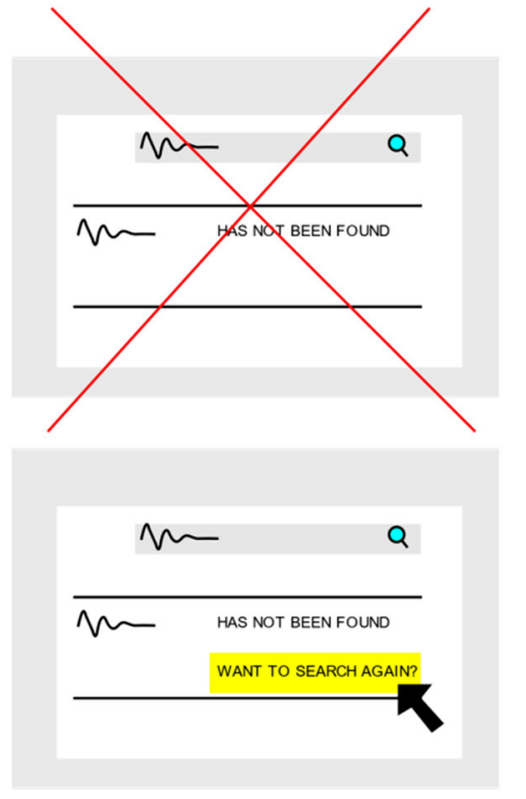

Fig. 19 List of specific design elements for 0 items. No-compliance and compliance

\section{Recommendation Q: list of specific design elements for 0 items}

This guideline recommends that in search systems, there is a specific design for the result " 0 elements". When a user searches for an item in a search field and that item is missing, the user becomes frustrated. The website must offer an alternative or suggestion [49].

Figure 19 shows two web pages. In the upper one, the result of any search indicates that there are no elements. This does not help the user, who probably tries the same search a second time. The web page below indicates that they have not found items in that search and asks the user if they want to try again.

\section{Recommendation R: respect the natural order of use of elements}

This guideline intends that all web pages respect a logical order in the placement of their elements, instead of pretending to be too different from the rest.

It is recommended to use this guideline mainly in input fields and buttons. These actions must have a "natural next step", identifiable, and close. The objective is to prevent the user from scanning the web page and making long cursor movements [32].

The natural order is to place the elements ordered from left to right and from top to bottom following the logic of the actions.

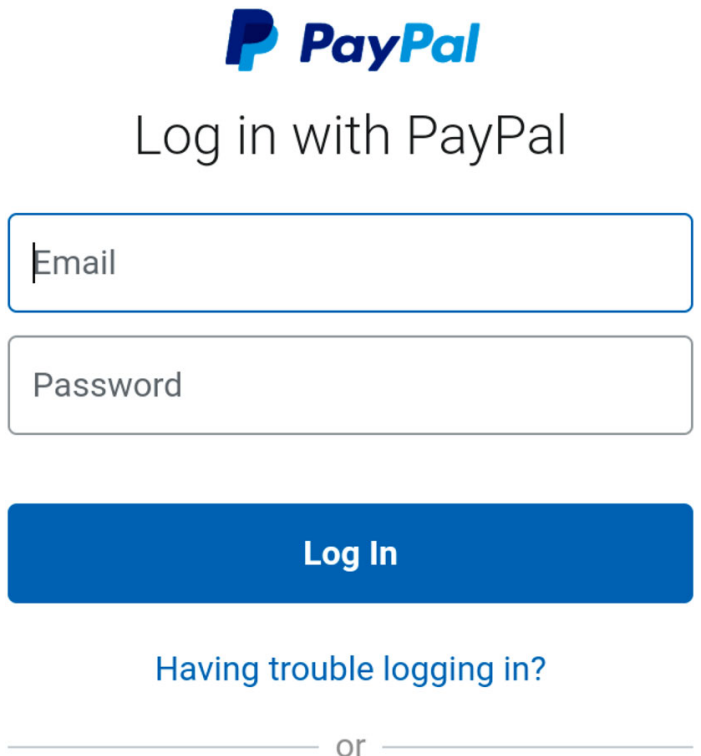

\section{Sign Up}

Fig. 20 Respect the natural order of use of elements [52]

For example, it can be applied at logins, where there are always identification fields and, just then, a button to start. This button can be placed below the last identification field or aligned to the left if there is more relevant information to put. For example, "have you forgotten your password?" This phrase can also be placed under the last identification field, aligned to the right.

Another way to order this properly would be to put the button just below and then the link to the alternative.

In Fig. 20, two identification fields are presented. Just below the button to $\log$ in. And below the button a link that helps the user in case of problems with the login.

\section{Recommendation S: prevent the user from remembering information}

It is important to prevent the user from having to remember things to navigate, especially information.

This guideline wants to offer recognition before the recall. That is, offer clues that prevent the user from trying too hard [53].

In the case of requesting regular information, suggestions, or selection of information may be included. This can be done as long as the information belongs to a group of known values. For example, countries, equipment in a vehicle, etc.

Figure 21 shows a country search field. When the user enters "ger", all the options that contain that letter order are displayed. For example, Algeria, Germany, Niger, and Nige- 


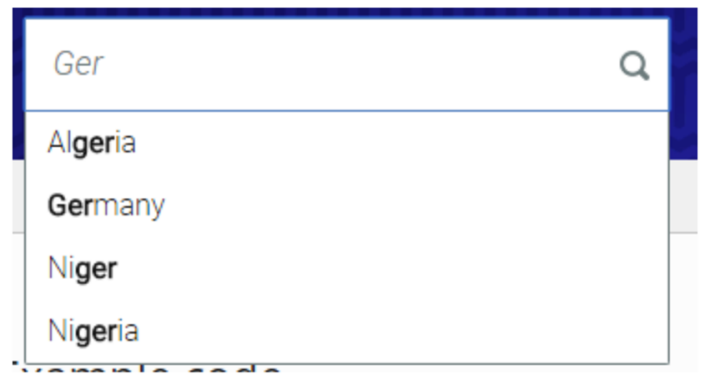

Fig. 21 Prevent the user from remembering information

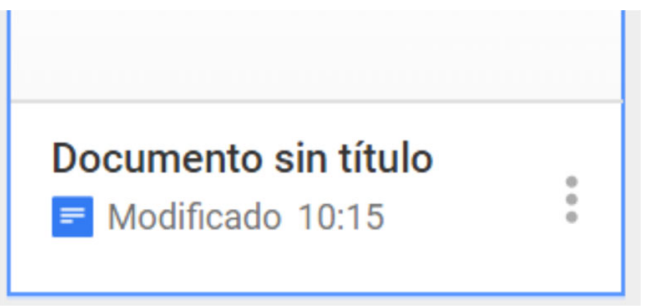

Fig. 22 Show dates as quickly as possible [54]

ria. If the user does not remember the exact word they are looking for, or if they are not sure how to spell it, this guideline would be helpful.

\section{Recommendation T: show dates as quickly as possible}

This guideline ensures that both dates and times are offered understandably.

Depending on the use or context of the element, time must be understandable. For example, full date, time that has elapsed plus full date in detail, etc.

It is very important to prevent the user from remembering or calculating dates. For example, how many days ago the user sent an e-mail. Another example, how many minutes have passed since the user made the shipment? [53]

Figure 22 shows the time elapsed since the last modification of a document.

\section{Recommendation U: indicate the number of elements in a list or category}

With this guideline, it is intended that a list or category of elements indicate the number of existing elements to inform the user.

This is especially important if such a quantity of elements (badges) is relevant to the application. Or if this amount is a list of favorite items, categories, or items in a shopping cart [37].

Figure 23 shows the total number of emails in two categories, in "Social" and "Promotions".

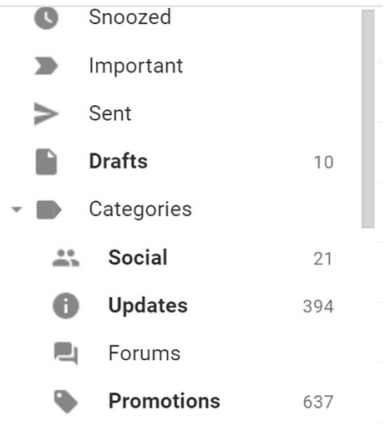

Fig. 23 The 3.21 Indicate the number of elements in a list or category [47]

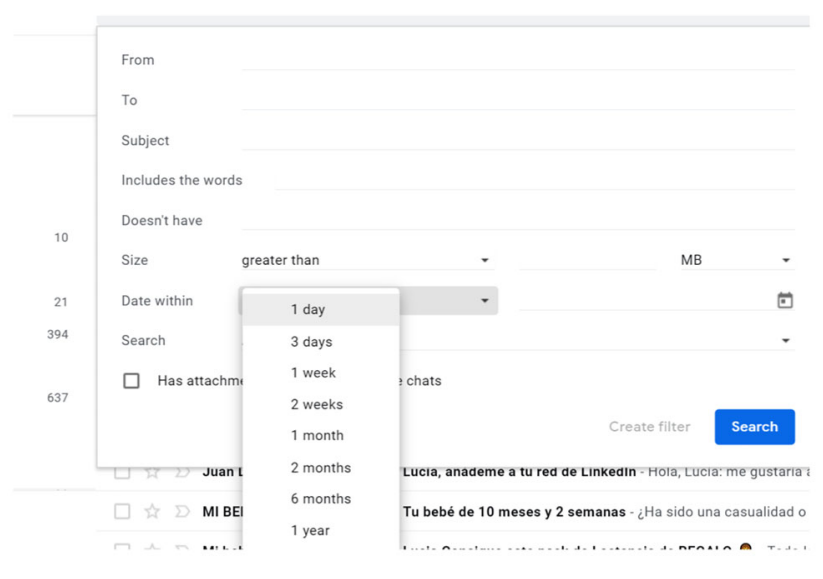

Fig. 24 Control of non-active items

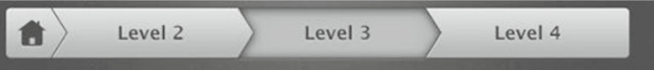

Fig. 25 Report that in which part of the application/task is the user

\section{Recommendation V: control of non-active items}

Non-active items must be disabled or hidden. If they are hidden, they can appear with a transition. When this guideline is not applied, the user loses efficiency [55]

Figure 24 shows a search for movements. There are two ways of searching. On one hand, looking for the number of the last movements. On the other hand, searching by month. Although there are two options, the user can only select one of the two. In this case, the search by the number of elements is selected, which means that the other search is disabled.

\section{Recommendation W: report that in which part of the application/task is the user}

This guideline recommends informing in which section or part of the application or task the user is located. For this, you can use bread crumbs or a highlight of the menu sections.

Figure 25 shows a highlight of Sect. 2 of the menu.

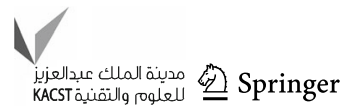




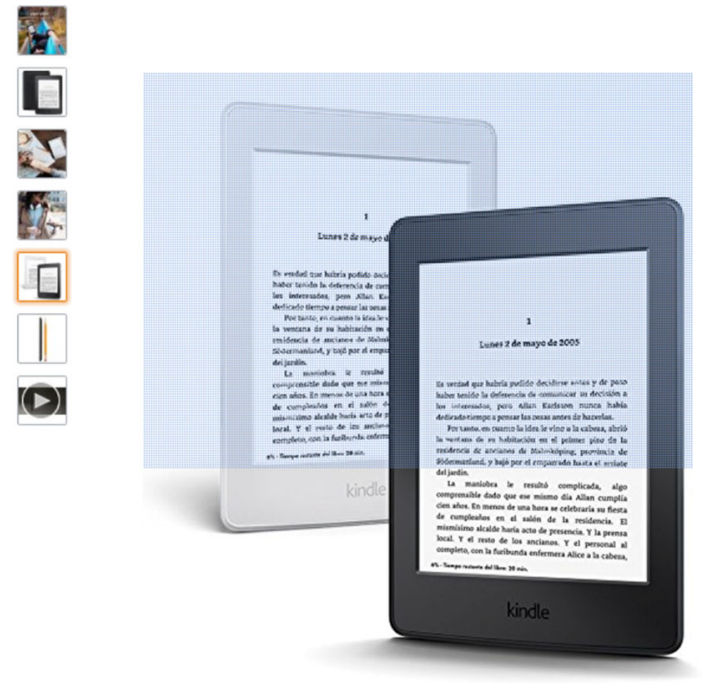

Fig. 26 Galley handling [56]

\section{Recommendation X: galley handling}

It is usually applied to image galleries, but could be used in other elements.

The number of items shown should be highlighted, as indicated in the pagination pattern.

In some cases, it is important that images can be zoomed in. For example, in items to buy. It is also useful to include thumbnails of the images, so that the user quickly identifies the image he wants to access [23].

A purchased item is presented in Fig. 25. The image is enlarged by focusing on it. Also, on the left, there is a series of miniature images that help the user to know the product better (Fig. 26).

\section{Results of the experiment}

The results of the experiment have been achieved according to Sect. 3 and considering the recommendations seen above (Sect. 4), which are:

1. Use color to increase recognition speed.

2. Use of images to increase recognition speed.

3. Highlighting dynamic changes on the website.

4. Limit the extension of tasks.

5. Task progress report.

6. Task progress report.

7. Repetition of main actions.

8. Grouped textual listings.

9. List of elements. Show key information.

10. List of elements. Limit key information.

11. Element listings. Sorting, filtering and search mechanisms.

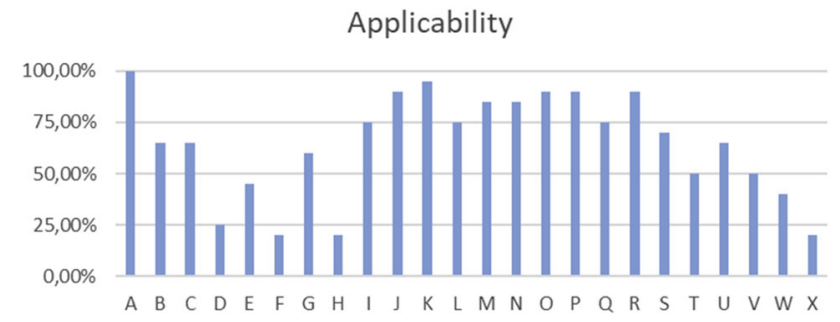

Fig. 27 Results of applicability

12. List of elements. Highlight item with focus.

13. List of elements. Avoid manipulation through menus.

14. List of elements. Avoid scroll.

15. List of items. Show the number of items listed.

16. List of specific design elements for 0 items.

17. Respect the natural order of use of elements.

18. Prevent the user from remembering information.

19. Show dates as quickly as possible.

20. Indicate the number of elements in a list or category.

21. Control of non-active items.

22. Report that in which part of the application/task is the user.

23. Galley handling.

This section includes the results of tests (a) and (b) both with the 24 recommendations previously seen.

\section{Objective 1: Test (a) "Innate" use of usability guidelines by developers}

Web developers receive training in guidelines on presenting information after developing the websites. With the help of a usability expert, the web developers themselves evaluate their websites once they have received the training. They evaluate the most applied guidelines: 0 means that the website should have used the analyzed guideline, but it was not used. 1 means that the pattern was applied. A guideline can be applied, but not fulfilled. This means that the web developer intended to use it, but did not know how to do it.

Figure 27 shows the results of the application of all the guidelines. The most neglected instructions are A (identifiable clickable areas of enough size), K (list of elements. Avoid zigzag), and J (list of elements. Limit key information). The error bar shows the difference in the percentage of application of the most applied and least-used guidelines.

In objective 1, the level of compliance is also studied. Figure 27 shows the application of each pattern. Figure 28 shows the level of compliance of each applied model.

Figure 28 shows the degree of compliance of each recommendation. Compliance refers to the level of correction when applying the guideline. That is, a well-applied pattern is said to approve compliance. As explained in the previous 
Compliance

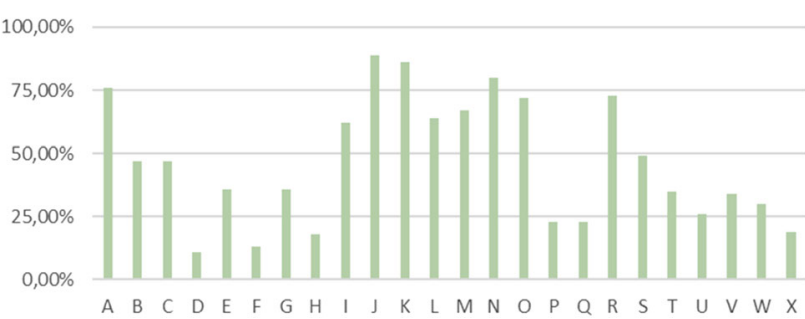

Fig. 28 Results of compliance

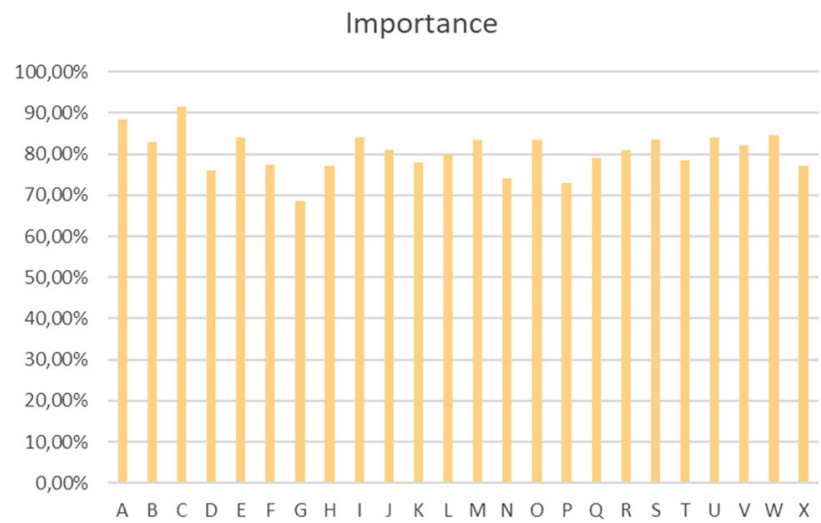

Fig. 29 Results of importance

section, the guidelines can be applied, see Fig. 27, but that said application is not well fulfilled, see Fig. 28. For example, guideline Q (list of specific design elements) is well remembered by web developers, which means that it is considered an applied guideline, but it is the second-worst compliment.

The best-fulfilled guidelines are the $\mathrm{J}$ (list of elements. Limit key information), K (list of elements. Avoid zigzag), and $\mathrm{N}$ (list of elements. Avoid manipulation through menus). The error bar shows the difference in the percentage of compliance of the most compliance and least-used guidelines.

\section{Objective 2: Test (b) "Important" use of usability guidelines by developers}

Figure 29 shows the degree of importance of each recommendation. It shows the importance that web developers give to each pattern after training. The guidelines considered least important are $\mathrm{C}$ (use of images to increase recognition speed), A (identifiable clickable areas of enough size), and W (report that in which part of the application/task is the user). The error bar shows the difference in the percentage of importance of the most important and least-used guidelines.

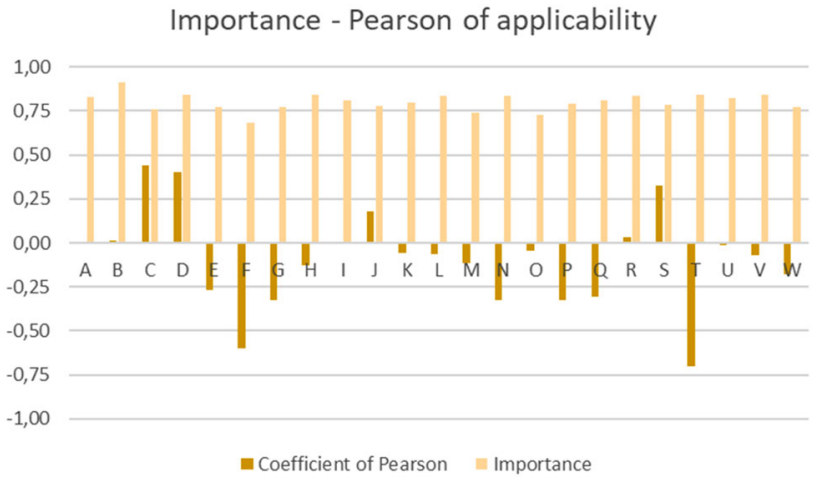

Fig. 30 Statically analysis of the importance

\section{Evaluation}

\section{Importance analysis}

In the results of tests $\mathrm{A}$ and $\mathrm{B}$, the relationships between the variables: importance, applicability, and level of compliance are analyzed. The graphs are presented with the data of the coefficient of determination of compliance ordered in decreasing form.

\section{Analysis of the importance}

In this section, the pattern with a greater relationship between variables is analyzed.

Conclusions are drawn about the relationship between their variables. Variables are importance, coefficient Pearson of application.

Figure 30 compares the degree of importance given to each recommendation and the coefficient of compliance determination of Pearson. This coefficient reflects compliance with the adjustment of a model to variable importance, which is what it is intended to explain. The standard deviation is the expected variation of the arithmetic mean. This article only publishes the scatter plots of those recommendations whose moderate ratio, with a value $-0.40>$ or $<0.40$, or high, with a value $-0.60>$ or $<0.60$.

Figure 30 states that the closest values between the coefficient of compliance determination and importance are given in recommendations $\mathrm{C}$ : use of images to increase recognition speed, and D: highlighting dynamic changes on the website. The rest of the coefficients seem to contradict the theory of relations, except the recommendations T: show dates as quickly as possible, and F: task progress report, which has an inverse relationship. These recommendations are analyzed below, in the following subheading.

Pearson's correlation coefficient is a linear measure of statistics that compares two quantitative random variables.

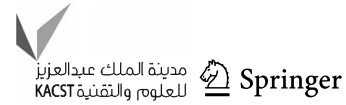


This study analyzes the compliance and applicability of each guideline, and compliance and importance.

The objective is to determine if the greater the importance of a higher compliance rate. That is, if the guideline is properly fulfilled, the more important your programmer gives it. And the same with the application of the guideline. That is if the guideline is applied correctly or incorrectly to greater importance given.

Unlike covariance, Pearson's correlation is independent of the measurement scale of the variables. Therefore, it is measured based on the Pearson coefficient to obtain the same index in all the guidelines.

To interpret the results, the dispersion diagram must be followed. It is used to analyze the force and direction of the linear direction between the variables. The value of the correlation coefficient can vary from -1 to +1 . The higher the absolute value of the coefficient, the stronger the relationship between the variables. An absolute value of 1 indicates a perfect linear relationship. A correlation close to 0 indicates that there is no linear relationship between the variables.

The sign of the coefficient indicates the direction of the relationship. If both variables tend to increase or decrease at the same time, the coefficient is positive and the line representing the correlation forms an upward slope. If one variable tends to increase, while the other decreases, the coefficient is negative, and the line representing the correlation forms a downward slope.

\section{Statistical analysis of the applicability}

There is no perfect positive correlation in any applicability analysis. This means that there is no sure proof that there is a relationship between the importance given to a guideline and its application. Even without knowing if this application is correct.

The ordinate shows compliance and the abscissa show the importance. Each web developer is represented by a coordinate point $(X i, Y i)$ in the graph.

A moderate relationship has been detected in recommendations C: use of images to increase recognition speed and D: highlighting dynamic changes on the website. A moderate relationship indicates which points are close to the line, but other points are far away. This means that there is only a moderate relationship between the importance variable and the applicability variable.

Figure 31 shows the dispersion diagram of recommendation C: use of images to increase recognition speed. It is moderate positive relationship is 0.44 . Its coefficient of determination $\left(R^{2}\right)$ is 0.19 and its covariance of 0.15 . The importance that web developers give to this recommendation is $91.5 \%$. The legend formula is the coordinates of the linear trend of the relation.

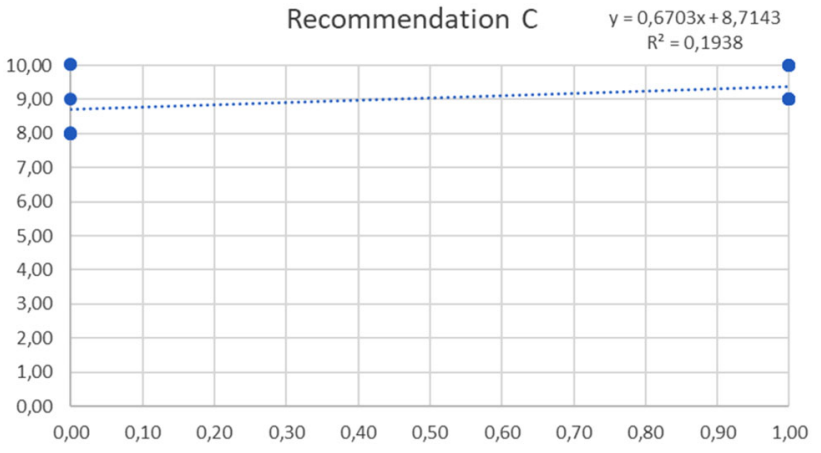

Fig. 31 Pearson coefficient of dispersion diagram of the applicability of the recommendation $\mathrm{C}$

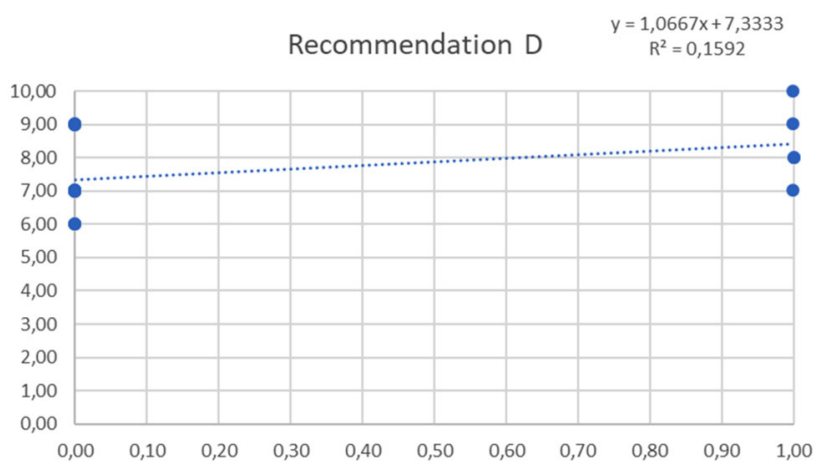

Fig. 32 Pearson coefficient of dispersion diagram of the applicability of the recommendation $\mathrm{D}$

Figure 32 shows the dispersion diagram of recommendation D: highlighting dynamic changes on the website. Its moderate positive relationship is 0.40 . Its coefficient of determination $\left(R^{2}\right)$ is 0.16 and its covariance of 0.2 . The importance that web developers give to this recommendation is $76 \%$. The legend formula is the coordinates of the linear trend of the relation.

Also, there is a high relationship in recommendation F: task progress report and T: show dates as quickly as possible.

In both the relationship is negative. This means that the points are located near the line, which indicates that there is a strong negative relationship between the variables. But that their relationship is negative, because as one variable increases, the other variable decreases. In this case, increasing the importance seems to decrease the application of the pattern.

Figure 33 shows the high negative ratio of recommendation F: task progress report. Pearson's coefficient is -0.60 . The coefficient of determination $\left(R^{2}\right)$ is 0.36 and the covariance -0.2 . The importance that web developers give to this recommendation is $77.5 \%$. The legend formula is the coordinates of the linear trend of the relation.

Figure 34 shows the high negative ratio of recommendation T: show dates as quickly as possible. The Pearson coefficient is -0.70 . The coefficient of determination $\left(R^{2}\right)$ 


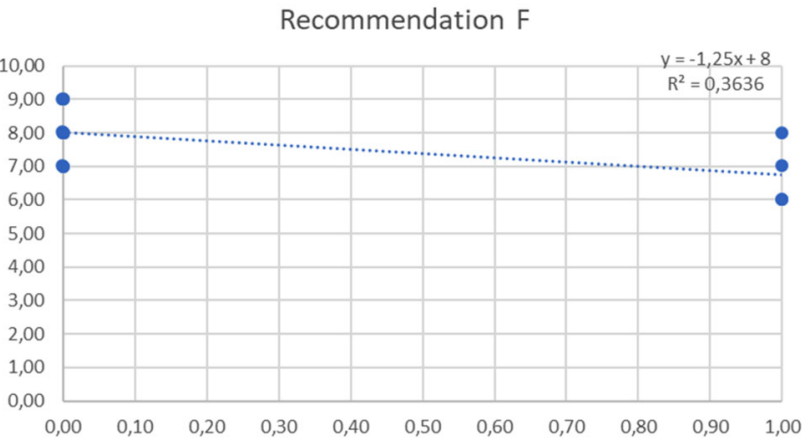

Fig. 33 Pearson coefficient of dispersion diagram of the applicability of the recommendation $\mathrm{F}$

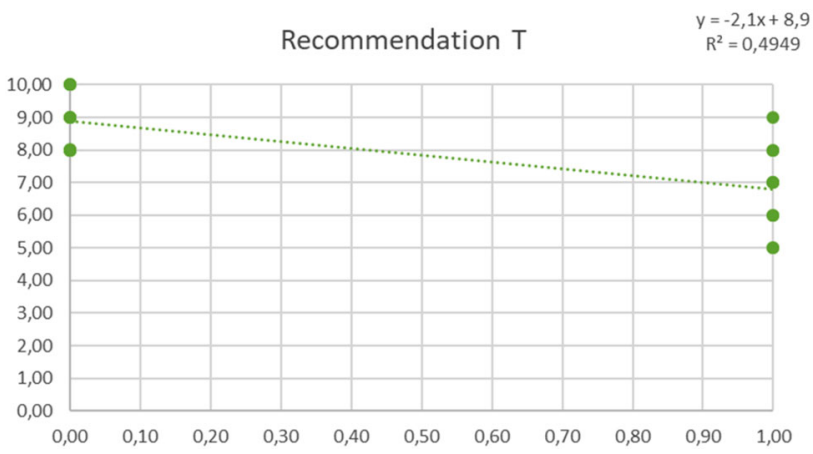

Fig. 34 Pearson coefficient of dispersion diagram of the applicability of the recommendation $\mathrm{T}$

is 0.49 and the covariance of -5.53 . The importance that web developers give to this recommendation is $78.5 \%$. The legend formula is the coordinates of the linear trend of the relation.

\section{Statistical analysis of the compliance}

In this section, the pattern with a greater relationship between variables is analyzed (Fig. 35).

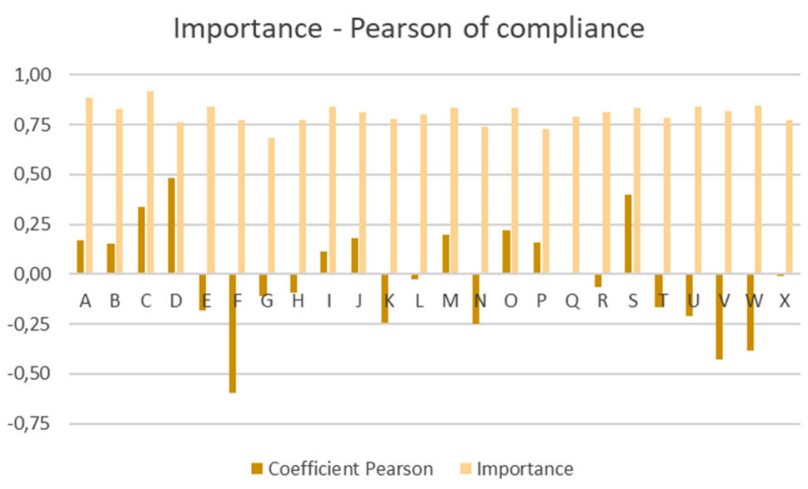

Fig. 35 Statically analysis of the importance

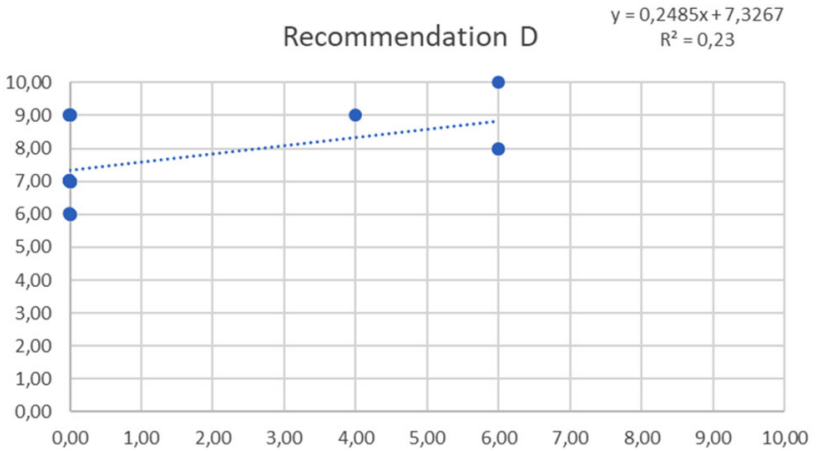

Fig. 36 Pearson coefficient of dispersion diagram of the compliance of the recommendation D

Conclusions are drawn about the relationship between their variables. Variables are importance, coefficient Pearson of compliance.

There is no perfect positive correlation in any applicability analysis. This means that there is no sure proof that there is a relationship between the importance given to a guideline and its application. Even without knowing if this application is correct.

The ordinate shows compliance and the abscissa show the importance. Each web developer is represented by a coordinate point $(X i, Y i)$ in the graph.

There is a moderate relationship in three recommendations, in recommendation D: highlighting dynamic changes on the website, $S$ : prevent the user from remembering information, F: task progress report, and V: control of non-active items.

The relationship of the variables of recommendations D: highlighting dynamic changes on the website and S: prevent the user from remembering information is positive, while that of recommendation F: task progress report and V: control of non-active items are negatives. This means that the greater the importance attached to the guidelines, there is greater compliance with them in positive relationships and less compliance in the negative.

Figure 36 presents the scatter plot of recommendation D: highlighting dynamic changes on the website. The Pearson coefficient is 0.47 . The coefficient of determination $\left(R^{2}\right)$ is 0.23 and the covariance of 1.24 . The importance that web developers give to this recommendation is $76 \%$. The legend formula is the coordinates of the linear trend of the relation.

Figure 37 presents the scatter plot of recommendation S: prevent the user from remembering information. The Pearson coefficient is 0.39 . The coefficient of determination $\left(R^{2}\right)$ is 0.16 and the covariance of 2.29 . The importance that web developers give to this recommendation is $83.50 \%$. The legend formula is the coordinates of the linear trend of the relation. 


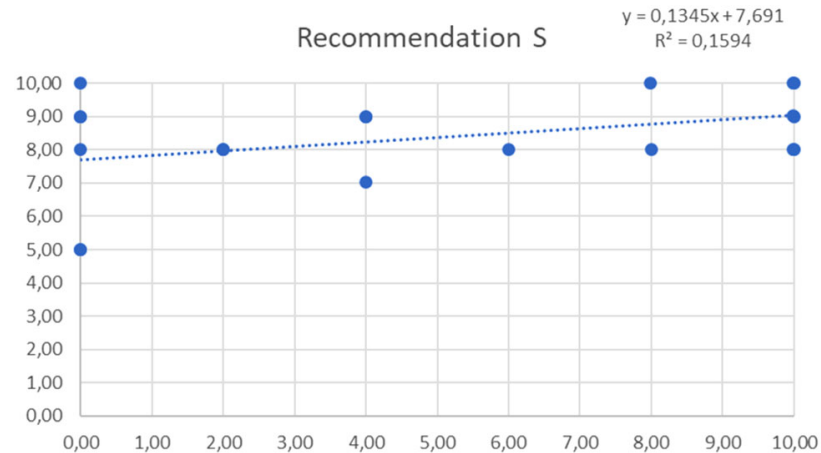

Fig. 37 Pearson coefficient of dispersion diagram of the compliance of the recommendation $\mathrm{S}$

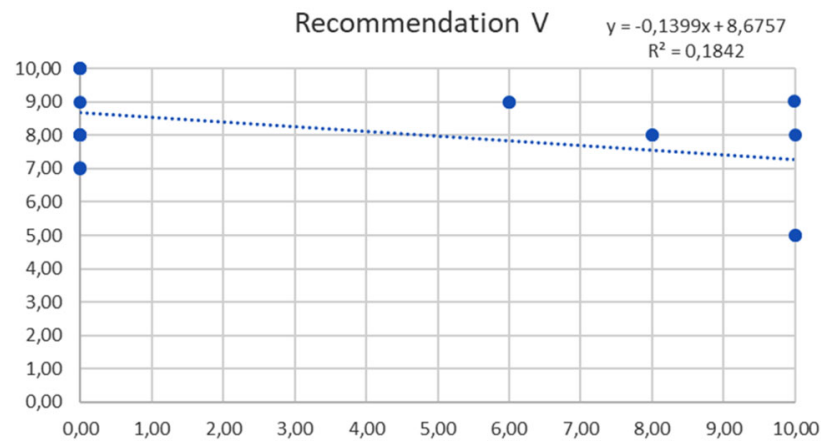

Fig. 38 Pearson coefficient of dispersion diagram of the compliance of the recommendation $\mathrm{V}$

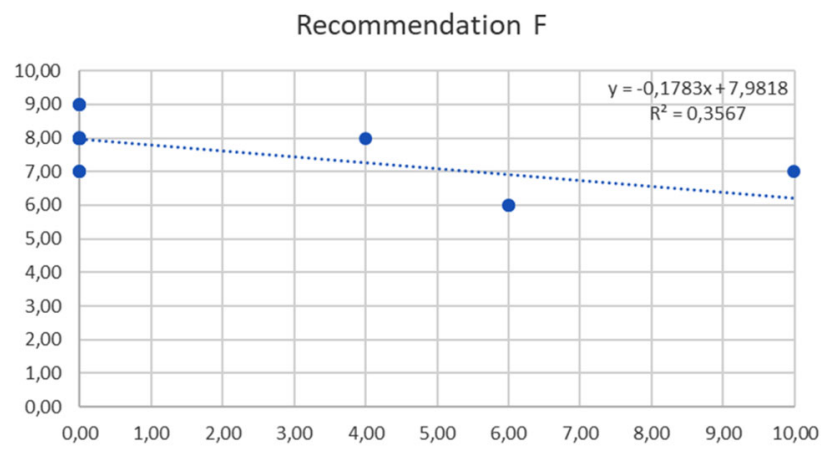

Fig. 39 Pearson coefficient of dispersion diagram of the compliance of the recommendation $\mathrm{F}$

Figure 38 presents the scatter plot of recommendation V: control of non-active items. The Pearson coefficient is 0.42 . The coefficient of determination $\left(R^{2}\right)$ is 0.18 and the covariance of -2.58 . The importance that web developers give to this recommendation is $82 \%$. The legend formula is the coordinates of the linear trend of the relation.

Figures 39, 40 present the scatter plot of recommendation F: task progress report. The Pearson coefficient is -0.59 . The coefficient of determination $\left(R^{2}\right)$ is 0.36 and the covariance of -1.38 . The importance that web developers give to this recommendation is $77.5 \%$. The legend formula is the coordinates of the linear trend of the relation.
Compliance - Coefficient Pearsonof compliance

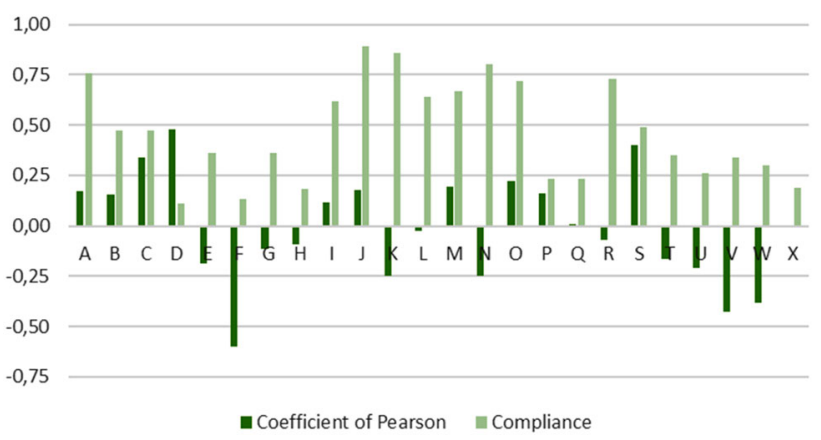

Fig. 40 Statically analysis of the compliance

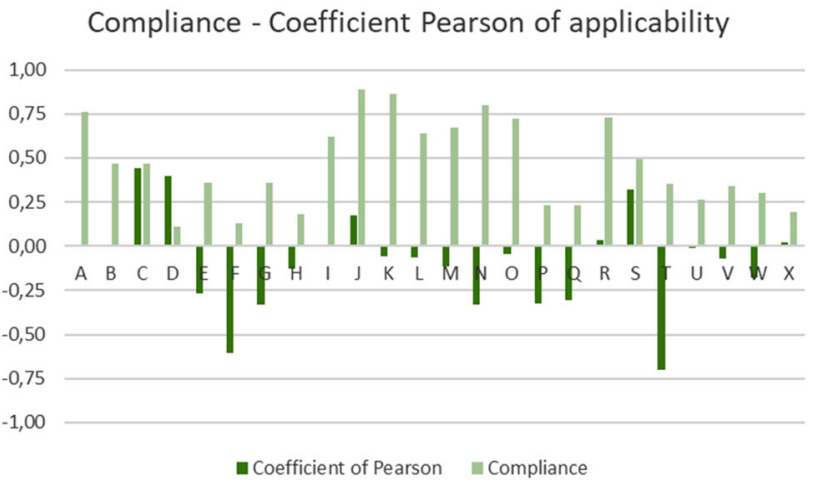

Fig. 41 Statically analysis of the compliance

\section{Compliance analysis}

The Pearson coefficient of compliance with the Pearson coefficient of applicability is compared with the compliance table.

Since the recommendations with an outstanding relationship have already been analyzed in the previous point, this section only offers a comparison with the compliance table.

Figures 39, 40 compare the level of compliance that is applied to each recommendation and the coefficient of Pearson that exists between importance and applicability. Figure 41 compares the level of compliance that is applied to each recommendation and the coefficient of Pearson that exists between importance and compliance.

Comparing both graphs, the difference in the relationship between compliance and applicability is analyzed. There is a noticeable difference in almost all recommendations. Highlights recommendation P: list of items. Show the number of items listed, which has a direct relationship in the analysis of compliance and an inverse relationship in the analysis of applicability. However, their relationship is not representative, since it is considered low and, in this study, only moderate or high relationships have been published. Its compliance is $23 \%$. There are similar cases, although with even less significant relationships, with recommendations $\mathrm{M}$ : list of elements. Highlight item with focus, O: list of elements. 
Applicability - Coefficient Pearson of compliance

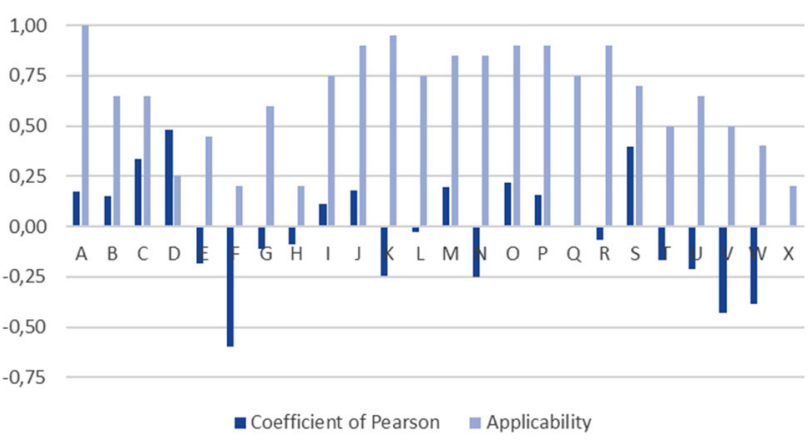

Fig. 42 Statically analysis of the applicability

Applicability - Coefficient Pearson of applicability

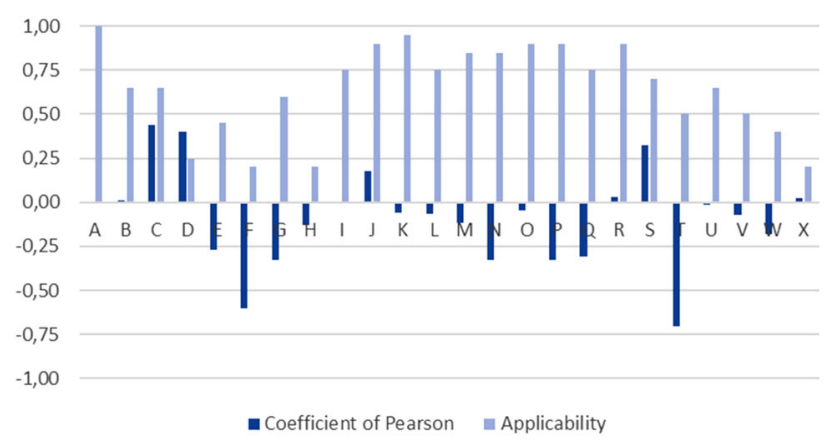

Fig. 43 Statically analysis of the applicability

Avoid scroll, and Q: list of specific design elements. Their compliance values are $67 \%, 72 \%$, and $23 \%$ respect.

\section{Applicability analysis}

The Pearson coefficient of compliance with the Pearson coefficient of applicability is compared with the applicability table.

Since the recommendations with an outstanding relationship have already been analyzed in the previous point, this section only offers a comparison with the applicability table.

Figure 42 compares the level of compliance that is applied to each recommendation and the coefficient of Pearson that exists between importance and applicability. Figure 42 compares the level of compliance that is applied to each recommendation and the coefficient of Pearson that exists between importance and compliance (Fig. 43).

Since the Pearson coefficients are the same as in the 6.2 compliance block, they will not be repeated in this section. Its applicability is analyzed. The applicability of recommendation P: list of items is $90 \%$, that of M: list of elements. Highlight item with focus is $85 \%$, that of $\mathrm{O}$ : list of elements. Avoid scroll is $90 \%$ and that of Q: list of specific design elements is $75 \%$.

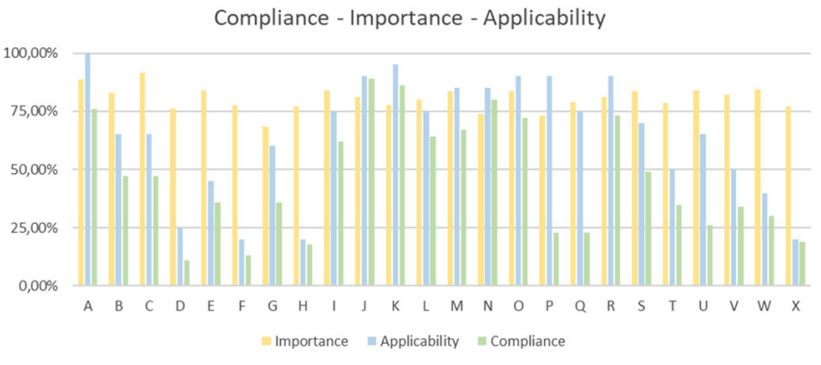

Fig. 44 Importance-compliance-applicability

\section{Discussion}

Figure 44 presents the relationship between the results of the three variables. The most prominent recommendations are probably $\mathrm{H}$ : grouped textual listings, $\mathrm{F}$ : task progress report, and D: highlighting dynamic changes on the website, who have greater fluctuation between the data of their variables. This may be because no recommendation is excessively unimportant, but all have values of importance above $74 \%$. This causes that when the levels of applicability and compliance are below $30 \%$, there is a lot of data variation and the less applied or worse complied recommendations highlight.

\section{Best-rated guidelines}

The best complied with recommendations are recommendation J: list of elements. Limit key information, a value of 4 $89 \%, \mathrm{~K}$ : list of elements. Avoid zigzag, a value of $86 \%$, and N: list of elements. Avoid manipulation through menus, a value of $80 \%$. All three are among the most applied innate. That is, even without knowledge or experience in web usability, they are recommendations that are often used and, also, are used correctly. The applicability of recommendation J: list of elements. Limit key information and K: list of elements. Avoid zigzags is $90 \%$, and that of recommendation $\mathrm{N}$ : list of elements. Avoid manipulation through menus is $85 \%$.

\section{Worst-rated guidelines}

The worst compiled recommendations and that require more training in web usability are recommendation $\mathrm{D}$ : highlighting dynamic changes on the website, a value of $11 \%$ compliance, recommendation $\mathrm{F}$ : task progress report, a value of $13 \%$, recommendation $\mathrm{H}$ : Grouped textual listings, the value of $18 \%$. The three worst compiled recommendations are also the least applied. This means that web developers always or almost always forget about them. The levels of applicability are between 20 and $25 \%$. Nor are they considered very important. That is, after training in web usability, developers do not consider these recommendations among the most

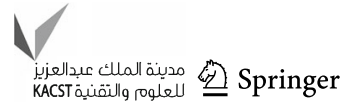


important, but rather those that are less important compared to others.

\section{Conclusions}

This research aims to investigate usability patterns in "Give information quickly and comprehensibly". For this, two experiments are carried out.

First, a team of 20 web developers with experience in web development but without knowledge of web usability is asked to design several websites. All web developers are unaware of the web usability recommendations that will be analyzed later. The objective is to find out if the application of any of these usability guidelines is innate.

Second, developers are trained in usability and a survey is conducted. The survey is divided into two parts. (1) Know the level of importance that developers attach to each of the recommendations once studied. (2) Evaluate their developments to know the level of compliance with these recommendations.

Our work aims to find out which recommendations are considered more and less important, which recommendations apply more and less, if such compliance is correct, and if there is a relationship between said importance and application.

There are moderate and high importance-applicability relationships in several of the recommendations already described. Not only direct relationships but also reverse. This means that the greater the importance is given, there is less application.

In response to Objective 1, the most forgotten recommendations are $\mathrm{F}$ : task progress report, $\mathrm{H}$ : grouped textual listings, and X: galley handling, which only applied $20 \%$ of the time. The most remembered recommendation is the A, applied $100 \%$ of the time.

In response to Objective 2, the worst-recommended recommendation is D: highlighting dynamic changes on the website, successfully using only $11 \%$. The best compliment is $\mathrm{J}$ : List of elements. Limit key information correctly fulfilled by $89 \%$.

The analysis carried out on recommendation $\mathrm{C}$ : use of images to increase recognition speed indicates that the developers attach great importance, $91.5 \%$. It is the most important recommendation according to the survey. It also indicates that there is a moderate relationship between the importance and applicability of the variables, with a Pearson coefficient of 0.44 . This means that the more important, the more application. Its application is $65 \%$. It can be considered that in more than half of web developers, there is an innate behavior during its application, since its use is considered important during the web development. Its compliance, however, is $47 \%$, so it is not a guideline that is innatametely complied with, but we can conclude that it requires specific training.
The analysis performed in recommendation D: highlighting dynamic changes on the website indicates that developers attach little importance compared to other guidelines, $76 \%$. It is the fourth-least important recommendation according to the survey. It also indicates that there is a moderate relationship between the importance and applicability of the variables, with a Pearson coefficient of 0.40 , and a moderate relationship between importance and better compliance, with a Pearson coefficient of 0.47 . This means that the more important, the more application and more compliance. Its application is $25 \%$. It can be considered that only a quarter of web developers innately apply it, since its use is considered unimportant during web development. Its compliance is $11 \%$, so it is not a guideline that is met correctly, but we can conclude that it requires a lot of specific training.

The analysis made in recommendation $\mathrm{F}$ : task progress report indicates that developers attach relative importance, $77.5 \%$. It is in the middle of the survey. It also indicates that there is a strong and inverse relationship between importance, with a Pearson coefficient of -0.60 . This means that the more important, the less application. Its application is $20 \%$. The third least applicable guideline during web development can be considered. Its compliance is $13 \%$, so it is not a guideline that is met correctly, but we can conclude that it requires a lot of specific training.

The analysis performed in recommendation $\mathrm{T}$ : show dates as quicklyas possible indicates that developers attach relative importance, $78.5 \%$. It is in the middle of the survey. It also indicates that there is a strong and inverse relationship between importance, with a Pearson coefficient of -0.70 . This means that the more important, the less application. Its application is $50 \%$. It may be considered that the seventh least applied guideline during web development. Its compliance is $35 \%$, so it is not a guideline that is met correctly, but we can conclude that it requires a lot of specific training.

The analysis performed in recommendation $\mathrm{S}$ : prevent the user from remembering information indicates that developers attach relative importance, $83.5 \%$. It is in the middle of the survey. It also indicates that there is a moderate relationship between compliance and importance, with a Pearson coefficient of 0.47 . This means that the more important, better compliance. Its application is $70 \%$. It can be considered applied by half of the developers during web development. Its compliance is $49 \%$ so it is a guideline that is met correctly and innate by approximately half of the web developers, and we can conclude that it requires specific training for the rest.

The analysis carried out in recommendation $\mathrm{V}$ : control of non-active items indicates that developers give medium importance, $82 \%$. It is in the middle of the survey. It also indicates that there is a moderate and inverse relationship between compliance and importance, with a Pearson coefficient of -0.42 . This means that the more important, the worse compliance. Its application is $50 \%$. It can be 
considered applied by half of the developers during web development. Its compliance is $34 \%$, so it is not a guideline that is correctly and innate by web developers, and we can conclude that it requires specific training.

The analysis carried out in recommendation $\mathrm{F}$ : task progress report indicates that developers attach the importance of $77.50 \%$. It is the seventh least important according to the survey. It also indicates that there is a high and inverse relationship between compliance and importance, with a Pearson coefficient of -0.59 . This means that the more important, the worse compliance. Its application is $20 \%$. This is, together with $\mathrm{H}$ : grouped textual listings and $\mathrm{X}$ : galley handling, the worst recommendation applied by engineers during the web development. Its compliance is $13 \%$, the secondworst complied, so it is not a guideline that is met correctly and innate by web developers, and we can conclude that it requires a lot of specific training.

Usability is a useful tool to measure the quality of use. This measurement is carried out by a user who interacts with the website. There are many published guidelines to improve the user experience on websites. However, there are no standardized guidelines.

The objective of this publication is to offer a useful grouping of the existing guidelines and to analyze the compliance with the web usability guidelines on quick and understandable information guidelines to offer possible academic solutions that solve possible gaps.

\section{Future research lines}

We have published the research carried out about Group 1, Group 3, and Group 4. In this work, also on Group 3. We want to disseminate the data of Group 5, which are the only ones we have not yet developed.

Acknowledgements We acknowledge our universities UNIR and UNIOVI for the facilities they have given us to develop this saga of research that we consider so important for the improvement of the computer community.

Author contributions All team members contribute to the work to the same extent.

\section{Compliance with ethical standards}

Conflict of interest All authors declare that they have no conflict of interest.

Open Access This article is licensed under a Creative Commons Attribution 4.0 International License, which permits use, sharing, adaptation, distribution and reproduction in any medium or format, as long as you give appropriate credit to the original author(s) and the source, provide a link to the Creative Commons licence, and indicate if changes were made. The images or other third party material in this article are included in the article's Creative Commons licence, unless indicated otherwise in a credit line to the material. If material is not included in the article's Creative Commons licence and your intended use is not permitted by statutory regulation or exceeds the permitted use, you will need to obtain permission directly from the copyright holder. To view a copy of this licence, visit http://creativecomm ons.org/licenses/by/4.0/.

\section{References}

1. González Crespo R, Pascual Espada J, Burgos D (2012) Social4all: Definition of specificadaptations in Web applications to improve accessibility. J Ambient Intell Smart Environ 4:563-564

2. Bader E, Schön EM, Thomaschewski J (2017) Heuristics considering UX and quality criteria for heuristics. Int J Interact Multimedia Artif Intell 4(6)

3. Nielsen (1995) 10 usability heuristics for user interface design. Nielsen Norman Group

4. Lodhi A (2010) Usability Heuristics as an assessment parameter: for performing usability testing. In: 2010 2nd Int. Conf. Softw. Technol. Eng., pp V2-256-V2-259. https://doi.org/10.110 9/ICSTE.2010.5608809

5. Paz F, Villanueva C, Rusu C, Roncagliolo S, Pow-Sang J (2013) Experimental evaluation of usability heuristics. In: 2013 10th Int. Conf. Inf. Technol. NewGener, pp 119-126. https://doi.org/10.11 09/ITNG.2013.23

6. Mariage C, Vanderdonckt J, Pribeanu C (2005) State of the art of web usability guidelines, pp 688-700

7. Alonso-Virgos L, Pascual Espada J, Rodríguez Baena L, Crespo R (2018) Design specific user interfaces for people with down syndrome using suitable WCAG 2.0 guidelines. J Ambient Intell Humaniz Comput. https://doi.org/10.1007/s12652-017-0539-8

8. Alonso-Virgós L, Pascual Espada J, González Crespo R (2019) Analysing compliance andapplication of usability guidelines and recommendations by Web Developers. Comput Stand Interfaces

9. Alonso-Virgós L, Pascual Espada J, González Crespo R (2019) Analysing compliance andapplication of usability guidelines on efficient and understandable controls. Comput Stand Interfaces

10. Purchase H, AllderJ, Carrington D (2000) User preference of graph layoutaesthetics: a UML study. Int. Symp Graph Draw (5-18)

11. Alonso-Virgós L, Pascual Espada J, Rodríguez Baena L, González Crespo R (2018) Design specific user interfaces for people with down syndrome using suitableWCAG 2.0 guidelines. J Ambient Intell Humaniz Comput 9(5):1359-1374

12. Green D, Pearson J (2011) Integrating website usability with the electronic commerceacceptance model. Behav Inf Technol 30(2):181-199

13. Gonzalvez-Cabañas J, Mochón F (2016) Behavior \& information technology. Int J Interact Multimed Artif Intell 3(6):6-15

14. Hearst M (2009) Search user interfaces

15. Bernard M (2002) Examining user expectations for the location of common e-commerce webobjects. Usability News 4(1):1-7

16. Alonso-Virgos L, Rodriguez Baena L, Pascual Espada J, Rodriguez Crespo R (2018) WebPage design recommendations for people with down syndrome based on users'experiences. sensors, vol 18

17. MacDonald L (1999) Using color effectively in computer Figures. IEEE Comput Graph Appl 19(4):20-35

18. Nielsen J (2001) Design guidelines for homepage usability. de Nielsen Norman Gr. https://www.nngroup.com/articles/113design-guidelines-homepage-usability/

19. Baldominos A, De Rada F, Sae Y (2018) DataCare: big data analytics solution for Intelligent Healthcare Management. Int J Interact Multimed Artif Intell 4(7)

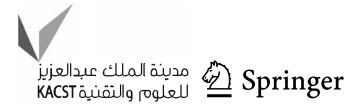


20. Grobelny J, Karwowski W, Drury C (2005) Usability of Figureal icons in the design ofhuman-computer interfaces. Int J Hum Comput Interact 18(2):167-182

21. Rauschenberger $M$, Olschner $S$, Cota $M$, Schrepp $M$, Thomaschewski J (2012) Measurement of user experience: a Spanish language version of theuser experience questionnaire (UEQ). In: 7th Iberian Conference onInformation Systems and Technologies (CISTI 2012). IEEE

22. Nielsen J, Loranger H (2006) Prioritizing web usability. New Riders Publishing, Thousand Oaks

23. Wang X (2008) Using cognitive walkthrough procedure to prototype and evaluate dynamicmenu interfaces: a design improvement. In: 2008 12th Int. Conf. Comput.Support. Coop. Work Des., pp 76-80. https://doi.org/10.1109/CSCWD.2008.4536959

24. Duan J (2010) Research on visualization techniques for web usability analysis. In: 2nd Int. Conf. Inf. Sci. Eng., pp 5366-5369. https:// doi.org/10.1109/ICISE.2010.5691330

25. Filip P, Lukáš L (2018) Webalyt: Implemetation of architecture for capturingweb user behaviors with feedback propagation. In: de 28th InternationalConference Radioelektronika (RADIOELEKTRONIKA). IEEE

26. Li C, Kit C (2005) Web structure mining for usability analysis. In: 2005 IEEE/WIC/ACMInt. Conf. Web Intell., pp 309-312. https:// doi.org/10.1109/WI.2005.160

27. Kortum P (2008) HCI beyond the GUI: design for haptic, speech, olfactory, and other nontraditional interfaces. Morgan Kaufmann Publishers Inc., San Francisco

28. Mahyavanshi N, Patil M, Kulkarni V (2017) A realistic study of user behavior forrefining web usability. In: 2017 Int. Conf. I-SMAC (IoT Soc. Mobile, Anal.Cloud), pp 450-453. https://doi.org/10.11 09/I-SMAC.2017.8058390

29. Schrepp J, Hinderks M (2017) Design and evaluation of a short version of the user experience questionnaire (UEQ-S). Int J Interact Multimed Artif Intell 4:103-108

30. Munim K, Islam I, Khatun M, Karim M, Islam M (2017) Towards developing a toolfor UX evaluation using facial expression. In: 2017 3rd Int. Conf. Electr. Inf.Commun. Technol., pp 1-6. https:// doi.org/10.1109/EICT.2017.8275227

31. Martin L (2009) A tool to estimate usability of Web 2.0 applications. In: 2009 11th IEEE Int. Symp. Web Syst. Evol., pp 83-86. https://doi.org/10.1109/WSE.2009.5631254

32. MM (2020) Usability testing case study: objective evaluation vs subjective evaluation [En línea]. https://medium. com/@ nurisanendita/usability-testing-case-studies-objectiveevaluation-vs-subjective-evaluation-b5e67d678e5e

33. Sik-Lányi C, Szúcs V, Guzsvinecz T (2017) Usability and colourcheck of a healthcareWEB-site. In: 2017 IEEE 30th Neumann Colloq, pp 111-116. https://doi.org/10.1109/NC.2017.8263263

34. Kirakowski J, Cierlik B (1998) Measuring the usability of web sites. In: Proc. hum. factors Ergon. Soc. Annu. Meet. vol 42, pp 424-428. https://doi.org/10.1177/154193129804200405

35. Tullis T, Fleischman S, McNulty M, Cianchette C, Bergel M (2002) An empirical comparison of lab and remote usability testing of web sites. In: U.P.A.Conference (ed) Usability Prof. Assoc. Conf.

36. Paz F, Paz F, Pow-Sang J, Collantes L (2014) Usability heuristics for transactional web sites. In: 2014 11th Int. Conf. Inf. Technol. New Gener. https://doi.org/10.1109/ITNG.2014.81

37. Quiñones D, Rusu C, Roncagliolo S (2014) Redefining usability heuristics fortransactional web applications. In: 2014 11th International conference on informationtechnology: new generations. IEEE

38. Papaloukas S, Patriarcheas K, Xenos M (2009) Usability assessment heuristics in new genre videogames. In: 2009 13th Panhellenic Conf. Informatics, pp 202-206. https://doi.org/10.1109/PCI. 2009.14
39. Chamba-Eras L, Jacome-Galarza L, Guaman-Quinche R, CoronelRomero E, Labanda-Jaramillo M (2017) Analysis of usability of universities Web portals using thePrometheus tool-SIRIUS. In: 2017 Fourth Int. Conf. eDemocracy eGovernment, pp 195-199. https://doi.org/10.1109/ICEDEG.2017.7962533

40. Granizo C, Yanez P, Ramirez D, Machado P (2011) Usability in e-government sites. In: 2011 Eighth Int. Conf. Inf. Technol. New Gener., pp 453-458. https://doi.org/10.1109/ITNG.2011.86

41. Hermawati S, Lawson G (2016) Establishing usability heuristics for heuristicsevaluation in a specific domain: Is there a consensus? Appl Ergon 56:34-51. https://doi.org/10.1016/j.apergo.2015.11.0 16

42. Borges J, Morales I, Rodriguez N (1996) Guidelines for designingusable World Wide Web pages. Conference companion on human factors in computing systems. ACM, New York

43. Goodui (2020) Data aside, years ago we started this project by listing out 75 general UIideas which to this day continue to raise questions [En línea]. https://goodui.org/

44. Mouaheb H, Fahli A, Moussetad M, Elijamali S (2012) The serious game: what educational benefits? Procedia Soc Behav Sci 46:5502-5508

45. Bevan N, Claridge N, Petrie H (2005) Guidelines and standards for web usability, Tenuta Simpl. Guid. Usability Access. Proc. HCI Int

46. Patterns U (2002) User interface design patterns [En línea]. https:// ui-patterns.com/

47. Gumussoy C (2016) Usability guideline for banking software design. Comput Human Behav 62:277-285. https://doi.org/10.101 6/j.chb.2016.04.001

48. Verdú E, García Bustelo P, Sánchez M, González Crespo R (2017) A systemto generate sign writing for video tracks enhancing accessibility of deaf people. Int J Interact Multimed Artif Intell

49. Swaak M, de Jong M, de Vries P (2009) Effects of information usefulness, visualattractiveness, and usability on web visitors' trust and behavioral intentions. In: 2009 IEEE Int. Prof. Commun. Conf., pp 1-5. https://doi.org/10.1109/IPCC.2009.5208719

50. Getto G, Thompson R, Saggi K (2016) Spurring UX innovation in academia through leanresearch and teaching. In: 2016 IEEE Int. Prof. Commun. Conf., pp 1-9. https://doi.org/10.1109/IPCC.201 6.7740527

51. Indriana M, Adzani M (2017) UI/UX analysis \& design for mobilee-commerce application prototype on Gramedia. com. In: 2017 4th InternationalConference on New Media Studies (CONMEDIA). IEEE

52. Conte T, Massollar J, Mendes E, Travassos G (2007) Usability evaluation based onweb design perspectives. In: First Int. Symp. Empir. Softw. Eng. Meas. (ESEM2007), pp 146-155. https://doi. org/10.1109/ESEM.2007.30

53. Alonso-Virgós L, Pascual Espada J, Thomaschewski J, González Crespo R (2019) Analizing compliance and application of usability guidelines and follow conventions recommendations by Web Developers. Comput Standers Interfaces

54. Silverbrook K, Lapstun P (2020) U.S. Patent Application No. $13 / 220,596$

55. Bonaiuto J, Itti L (2006) The use of attention and spatial information for rapid facial recognition in video. Image Vision Comput 24(6):557-563

56. Photobox (2020) En línea. https://www.photobox.es/

57. Teevan J, Dumais S, Liebling D (2010) A longitudinal study of how highlighting web content change affects people's web interactions. ACM, New York, pp 1353-1356

58. Minimamente (2020) En línea. https://www.minimamente.com/ project/magic/

59. Paternò F, Paganelli L (2020) Evaluación automática remota de sitios web basada en modelos de tareas y monitoreo del navegador. de CHI'01, resúmenes extendidos sobre factores humanos en los sistemas informáticos. ACM, New York, pp 283-284 
60. Facebook (2020) En línea. https://www.facebook.com

61. Jankowski J (2013) Increasing website conversions using content repetitions with different levels of persuasion. de Asian Conference on Intelligent Information and Database Systems. Springer, Berlin, Heidelberg, pp 439-448

62. Gmail (2020) En línea. https://www.gmail.com

63. Borges J, Morales I, Rodriguez N (1996) Guidelines for designing usable World Wide Web pages. de conference companion on human factors in computing systems. ACM, New York, pp 277-278

64. Medina N, Burella J, Rossi G, Grigera J, Luna E (2010) An incremental approach for building accessible and usable web applications. de International Conference on Web Information Systems Engineering. Springer, Berlin, Heidelberg, pp 564-577

65. elcorteinglés (2020) En línea. https://www.elcorteingles.es

66. Logitravel (2020) En línea. https://www.logitravel.com/

67. Paypal (2020) En línea. https://www.paypal.com/es/home

68. Schultz E, Proctor R, Lien M, Salvendy G (2001) Usability and security an appraisal of usability issues in information security methods. Comput Secur 20(7):620-634
69. Google (2020) En línea. https://www.google.es/

70. Amazon (2020) En línea. https://www.amazon.es/

71. Garcia-Lopez E, Garcia-Cabot A, Manresa-Yee C, de-Marcos L, Pages-Arevalo C (2017) alidation of navigation guidelines for improving usability in the mobile web. Comput Stand Interfaces 52:51-62. https://doi.org/10.1016/j.csi.2017.01.011

Publisher's Note Springer Nature remains neutral with regard to jurisdictional claims in published maps and institutional affiliations. 